\title{
ESTUDO DA MICROFLORA DE DERIVADOS DO LEITE COMO ÍNDICE DE QUALIDADE
}

CLAUDIO ROSA GALLO

Orientador: Dr. Antonio 3. de Oliveira

Dissertação apresentada à Escola Superior de Agricultura "Luiz de Queiroz", da Universidade de São Paulo, para obłenção do título de Mestre em Microbiologia Agrícola.

\author{
PIR A C I C A B A \\ Estado de São Paulo - Brasil \\ Outubro, 1978
}


Aos meus pais, irmãos

e $\bar{a}$ Cristina

$D E D I C O$ 
o autor expressa seus agradecimentos:

Ao Conselho Nacional de Pesquisas (CNPq) e ao Departamento de Tecnologia Rural, da Escola Superior de Agricultura "Luiz de Queiroz", da Universidade de São Paulo, pelos recursos que ofereceram, sem os quais não seria possivel a realização do presente trabalho.

Ao Professor Dr. Antonio Joaquim de 0liveira, pela valiosa co laboração, estímulo e compreensão como orientador.

Ao Professor Dr. João Gustavo Brasil Caruso, pelas sugestões apresentadas.

Aos Funcionärios do Departamento de Tecnologia Rural, da Escola Superior de Agricultura "Luiz de Queiroz", pelos valiosos auxilios prestados.

Ao Sr. Paulo Josē de Gäspari, pelos serviços de datilografia, impressão e encadernação.

E a todos que direta ou indiretamente colaboraram pa ra a realização deste trabalho. 


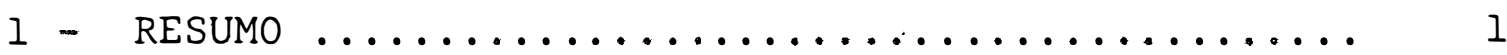

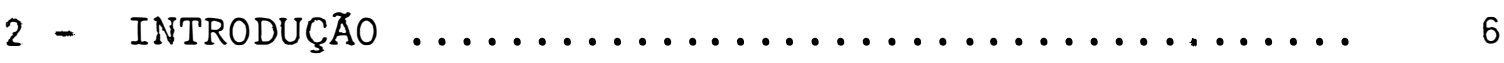

3 - REVISÃo DE LITERATURA ..................... 10

3.1 - Contagem Total .................... 10

3.2 - Coliformes ...................... 12

$3.3-$ staphyzococcus ................. 15

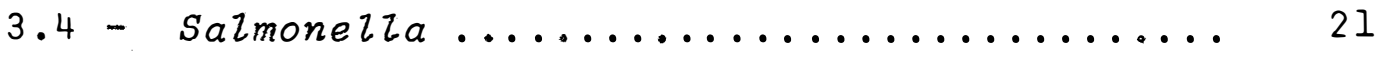

3.5 - Bactérias Proteoliticas ............. 25

3.6 - Bactérias Lipoliticas .............. 27

3.7 - Bactērias Psicrotröficas ............. 30

3.8 - Bactérias Termöfilas .............. 34

$3.9-$ Enterococos $\ldots \ldots \ldots \ldots \ldots \ldots \ldots \ldots \ldots \ldots \ldots \ldots$

3.10 - Fungos e Leveduras ................ 36

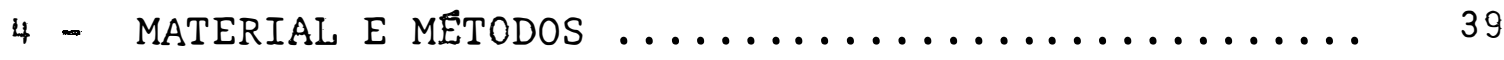

4.1 - Contagem Total ................... 40

4.2 - Coliformes ....................... 40

$4.3-$ staphyzococcus .......................... 41

$4.4-$ Salmonerza....................... 42

$4.5-$ Proteoliticos .................... 43

$4.6-$ Lipoliticos $\ldots \ldots \ldots \ldots \ldots \ldots \ldots \ldots \ldots \ldots \ldots$ 
Pàgina

4.7 - Psicrotróficos ................. 43

4.8 - Termófilos ................... 44

4.9 - Enterococos .................... 44

4.10 - Fungos e Leveduras ................ 44

4.11 - Esporulados Aeróbicos .............. 45

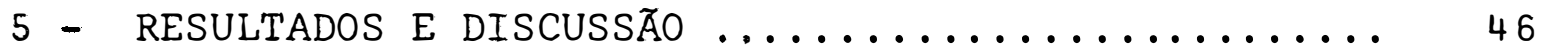

5.1 - Queijos ....................... 46

5.2 - Leite em Pö ..................... 56

5.3 - Manteigas ..................... 61

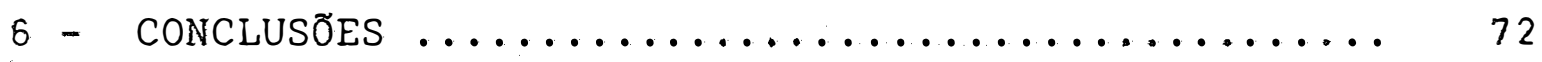

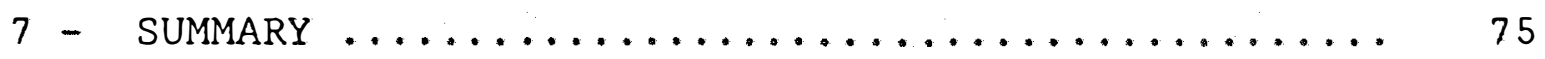

8 - LITERATURA CITADA ..................... 79 
$1-$ RESUMO

Este trabalho foi realizado para se constatar a presença de microrganismos patogênicos e deterioradores em alguns derivados do leite, tais como: queijos (Prato, Minas Frescal e Provolone), manteigas (come sem sal) e leite em pó (integral e desnatado). Amostras comerciais foram tomadas e analisadas para: Contagem Total, Coliformes Totais, Coliformes Fecais, StaphyZococcus, Psicrotróficos, Termöfilos, Proteo líticos, Lipolíticos, Enterococos, Salmonella, Fungos e Le veduras.

0 isolamento desses organismos seguiu as especifica ções descritas por SHARF (1972). A identificação foi feita de acordo com Standard Methods for the Examination of Dairy Pro- 
ducts (A.P.H.A., 1972), Bergey's Manual of Determinative Bacte riology (BUCHANAN e GIBBSONS, 1975) e Laboratory Exercices for Food Microbiology (BANWART, 1975).

As seguintes variações de contaminação por grama foram encontradas para queijos Prato, Minas Frescal e Provolone, respectivamente: Contagem Total: $8,0 \times 10^{6}$ à $2,3 \times 10^{7}, 1,6$ $\times 10^{8}$ à $2,2 \times 10^{8}$ e $1,0 \times 10^{7}$ à $2,0 \times 10^{7} ;$ Coliformes Totais: $6,3 \times 10^{2}$ à $2,0 \times 10^{3}, 8,5 \times 10^{4}$ à $1,7 \times 10^{5}$ e $3,0 \times 10^{2}$ à $8,8 \times 10^{2}$; Escherichia coli: $4,0 \times 10^{2} \mathrm{a} 1,1 \times 10^{3}, 2,9 \times$ $10^{4}$ à $1,6 \times 10^{5}$ e nenhuma amostra de queijo tipo Provolone mostrou a presença desse microrganismo; Coliformes Fecais: 4,0 $x$ $10^{2} \mathrm{a} 1,2 \times 10^{3}, 4,0 \times 10^{4}$ à $1,6 \times 10^{5}$ e nentum coliforme fecal foi detectado nas amostras de queijo tipo provolone; Staphylococcus: $1,1 \times 10^{5}$ à $2,3 \times 10^{5}, 1,7 \times 10^{6}$ à $1,9 \times 10^{6}$ e $7,3 \times 10^{5}$ à $1,2 \times 10^{6} ; 5$. aureus: $2,9 \times 10^{4}$ à $4,4 \times 10^{4}$, $3,3 \times 10^{5}$ à $3,7 \times 10^{5}$ e $1,2 \times 10^{4}$ à $2,3 \times 10^{l} ;$ Termófilos: $1,0 \times 10^{1}$ à $1,7 \times 10^{2}$, ausência nas amostras de queijo tipo Minas Frescal analisadas e $7,2 \times 10^{2}$ à $9,9 \times 10^{2}$, para as amostras de queijo tipo Provolone; Psicrotröicos (790/10 dias): nenhum à $1,3 \times 10^{2}, 2,5 \times 10^{2}$ à $7,9 \times 10^{2}$ e ausência nas amostras de queijo tipo Provolone analisadas; Psicrotróficos (219C/25 horas): nenhum a $1,5 \times 10^{2}, 2,0 \times$ $10^{2} \bar{a} 8,0 \times 10^{2}$ e ausência nas amostras de queijo tipo Provolone analisadas ; Proteoliticos: $2,6 \times 10^{2}$ a $6,4 \times 10^{2}$, $4,0 \times 10^{4}$ à $7,8 \times 10^{4}$ e $2,0 \times 10^{4}$ à $1,2 \times 10^{5} ;$ Lipolíticos: 
$1,0 \times 10^{3}$ à $1,7 \times 10^{3}, 2,7 \times 10^{4}$ à $9,1 \times 10^{4}$ e $2,3 \times 10^{4}$ à $2,4 \times 10^{4} ;$ Enterococos: $1,2 \times 10^{4} \overline{\mathrm{a}} 2,5 \times 10^{4}, 1,3 \times 10^{5} \overline{\mathrm{a}}$ $2,8 \times 10^{5}$ e $2,9 \times 10^{4}$ à $7,7 \times 10^{5}$; Fungos e Leveduras: $1,5 \times$ $10^{4}$ à $1,6 \times 10^{5}, 2,4 \times 10^{3}$ à $7,0 \times 10^{3}$ e $5,1 \times 10^{4}$ à 5,4 x $10^{4}$; Salmonelza: uma amostra de queijo tipo Prato e uma de queijo tipo Minas Frescal foram positivas para esse organismo e todas as amostras de queijo tipo Provolone foram negativas. As contagens por grama para as amostras de mantei gas com sal e sem sal, foram respectivamente: Contagem Total: $1,1 \times 10^{6}$ à $1,5 \times 10^{6}$ e $1,8 \times 10^{6}$ à $2,5 \times 10^{6}$; Coliformes To tais: $1,0 \times 10^{4}$ à $1,8 \times 10^{4}$ e $2,5 \times 10^{4}$ à $2,8 \times 10^{4} ; E$. CO$Z_{i}$ : ausência nas amostras de manteiga com sal e nenhum à 6,0 $x 10^{2}$ nas amostras de manteiga sem sal; Coliformes Fecais: nenhum coliforme fecal foi detectado nas amostras de manteiga com sal e nenhum à $6,0 \times 10^{2}$ nas amostras sem sal; Staphylococcus: $1,6 \times 10^{4}$ à $1,8 \times 10^{4}$ e $8,6 \times 10^{3}$ à $9,9 \times 10^{3} ; S$. aureus: nenhum à $3,2 \times 10^{3}$ e $8,0 \times 10^{2}$ à $1,8 \times 10^{3}$; Termöf los: $1,3 \times 10^{2}$ à $2,0 \times 10^{2}$ e $3,1 \times 10^{2}$ à $4,4 \times 10^{2}$; Psicrotrōficos (78C/10 dias): $7,3 \times 10^{2}$ a $8,1 \times 10^{2}$ e $1,3 \times 10^{4}$ à $1,7 \times 10^{4} ;$ Psicrotróficos (219C/25 horas): $6,8 \times 10^{2}$ à 8,1 $\times 10^{2}$ e $1,1 \times 10^{4}$ à $1,5 \times 10^{4} ;$ Proteolíticos: $1,6 \times 10^{4}$ à $2,0 \times$ $10^{4}$ e $1,1 \times 10^{5}$ à $1,2 \times 10^{5}$; Lipolíticos: $1,0 \times 10^{3} \bar{a} 1,1 \times 10^{3} \mathrm{e}$ $1,1 \times 10^{3}$ à $1,7 \times 10^{3} ;$ Enterococos: $7,0 \times 10^{1}$ à $1,3 \times 10^{2} \mathrm{e}$ $2,7 \times 10^{2}$ à $5,6 \times 10^{2} ;$ Fungos e Leveduras: $9,8 \times 10^{3}$ à 1,0 $\times 10^{4}$ e $9,7 \times 10^{3}$ à $1,4 \times 10^{4} ;$ Salmonella: foi detectada em 
uma amostra de manteiga com sal e em uma amostra de manteiga sem $s$ a 1 .

Para as amostras de leite em pó integral e leite em pó desnatado, as contagens foram respectivamente: Contagem To tax: $9,2 \times 10^{5}$ à $1,1 \times 10^{6}$ e $3,2 \times 10^{5}$ à $8,6 \times 10^{5} ;$ nem col $\underline{\text { i }}$ formes e nem staphylococcus foram detectados nas amostras de leite epó analisadas; Termófilos: $3,2 \times 10^{2}$ à $6,1 \times 10^{2}$ e $5,0 \times 10^{\prime} \mathrm{a} 1,1 \times 10^{2}$; Psicrotróficos (79C/10 dias e $219 \mathrm{C} /$ 25 horas) e Enterococos: não foram encontrados nas amostras a nalisadas: Proteolíticos: $1,6 \times 10^{3}$ à $1,9 \times 10^{3}$ e $9,5 \times 10^{2}$ à $1,3 \times 10^{3} ;$ Lipolíticos: $6,0 \times 10^{1}$ à $2,3 \times 10^{2}$ e $5,0 \times 10^{l}$ à $1,6 \times 10^{2}$; Fungos e Leveduras: $1,5 \times 10^{2}$ a $6,7 \times 10^{2}$ e nenum à $4,2 \times 10^{1}$; Esporulados Aeróbicos: $5,0 \times 10^{2}$ à $6,3 \times 10^{2}$ e $5,5 \times 10^{1}$ à $1,7 \times 10^{2} ;$ Salmonelza: todas as amostras foram negativas para esse microrganismo.

As altas contagens verificadas para Contagem Total, Coliformes Totais, Coliformes Fecais, S. aureus, Enterococos, Proteoliticos, Lipoliticos e Psicrotróficos na maioria das amostras de derivados do leite analisadas nesse trabalho, e a preseaça de Salmonella em algumas delas, revelam que as mesmas devem ser consideradas impróprias ao consumo humano, uma vez que, a maioria das contagens de microrganismos patogêni cos, está acía dos padrões estabelecidos pela Comissão Nacional de Normas e Padrões para Alimentos. 
Por outro lado, essas altas contagens microbianas, podem ser indicadoras de mâs condições higiênicas: nas indús trias de laticínios, no transporte e na distribuição desses produtos. 
o leite e seus diversos derivados, têm importância primordial em nossa alimentação diäria. Esses alimentos nos fornecem uma alta soma de carboidratos, gorduras, proteínas, mi nerais e vitaminas, e, como consequência de sua excelente composição, aliada ao fato de ter um $p H$ favorável ao crescimento de microrganismos e bastante umidade disponivel, constituem-se também em substrato ótimo para um grande nümero de microrganis mos, principalmente as bactërias.

Muitas das bactérias encontradas comumente no leite e seus derivados são de pequena importância em relação à quali dade do produto. Outras porém são agentes de deterioração, de 
vendo obviamente serem evitadas ou destruídas. Outras ainda são de natureza patogênica e logicamente são as mais importan tes no que concerne à saúde pública.

Assim, a indústria de laticínios nos dä um excelente exemplo de um campo onde os microrganismos (bactérias, leveduras e fungos), são de grande importância tanto do ponto de vista tecnológico como da conservação e qualidade dos produtos finais. Nesta indústria, a destruição de microrganismos indesejāveis, bem como a utilização dos que são desejäveis, exigem muita atenção.

os microrganismos e seus metabölitos são indesejäveis no leite e seus derivados, quando capazes de provocar altera ções no sabor e aroma elou características físicas, ou quando capazes de causar distúrbios de ordem fisiológica ao homem, ou seja, quando se constituem em microrganismos patogênicos.

A presença de microrganismos indesejáveis no leite e seus derivados, geralmente é devida à:

a) Mäs condições de higiene na obtenção do leite;

b) Pasteurização e esterilização inadequadas;

c) Falta de cuidados higiênicos durante o processamento;

d) Má higienização e assepsia dos equipamentos;

e) Más condições de armazenamento e tipo de embalagem, já que nessa fase pode ocorrer recontaminação do produto, ou condições favoráveis ao crescimento de microrganis mos. 
A temperatura se constitui num fator extremamente $\vec{u}-$ til no controle de microrganismos. Baseado nos ótimos, máxi mos e mínimos de temperatura, para cada microrganismo, sua des truição pode ser conseguida por aplicação de temperaturas que ultrapassem o seu mäximo ou mínimo, respectivamente. Como os organismos vivos compõem-se largamente de ägua, o limite mais baixo para o seu desenvolvimento é rigidamente estabelecido pe la temperatura de congelamento da água. 0 limite superior é estabelecido pela instabilidade térmica dos constituintes químicos da matéria viva, ou seja, proteínas e ácidos nucléicos, substâncias essas rapidamente destruídas à temperaturas entre 50 e 909 C (STANIER et alii, 1969).

Para cada organismo hä uma curva de crescimento característica, na qual se observam temperaturas minima, ótima e máxima para o crescimento. A temperaturas próximas do mínimo, todas as reações químicas da célula se processam lentamente a taxa de crescimento é consequentemente baixa. Nessa re gião, um pequeno aumento de temperatura produz um enorme aumen to na taxa de crescimento. A medida que se aproxima da temperatura ótima, o aumento na taxa de crescimento para um dado au mento de temperatura, torna-se cada vez menor (STANIER et alii, 1969). Por outro lado, um aumento de temperatura, acima do ótimo, produz um rápido declíneo na taxa de crescimento.

No processamento de derivados de leite, o calor e o frio são dois fatores extremamente importantes. 0 primeiro u- 
sado para destruição dos possíveis contaminantes presentes e o segundo como agente de conservação, mantendo a velocidade das reaçôs enzímicas, que possam ocorrer a níveis relativamente baixos, ou, como inibidor do crescimento de microrganismos, que possam ter sobrevivido ao tratamento térmico.

Embora as técnicas utilizadas no processamento, emba lagem e distribuição do leite e seus derivados, estejam em constantes progressos, ainda são encontrados nos producos finais, microrganismos patogênicos que podem trazer sérias infec ções e intoxicações alimentares, bem como, microrganismos causadores de defeitos, que tornam o produto de baixa qualidade para o consumo.

o presente trabalho visou a caracterização desses microrganismos, procurando estabelecer, através dos níveis de microrganismos patogênicos elou deterioradores do produto, uma relação entre a qualidade microbiológica do produto e as atuais condições de processamento e distribuição de alguns derivados do leite. 
10.

3 - REVISAOO BIBLIOGRAFICA

3.1 - Contagem Total.

ROGERS (1915), já indicava contagem total como um delicado critério de qualidade.

KILBOORNE (1920), enfatizou o perigo de se usar con tagens totais como ünica meifp para avaliar a qualidade de amostras de leite.

HOBBS e GILBERT (1974), colocam o método de conta gem total como um importante método auxiliar na determinação da qualidade de um alimento, já que existe um perigo potencial de encontrarmos microrganismos patogênicos e/ou deteriorado - 
res, quando altas contagens microbianas são observadas em alimentos.

Os primeiros trabalhos de comparação de incubação pa ra contagens totais de bactérias em placas, para leite cru e produtos de leite, foram feitos por PEDERSON e YALE (1934), que indicaram que à $329 \mathrm{C}$ conseguem-se maiores e mais representativas contagens que à $379 \mathrm{C}$, o que concorda com as recomendações da $13^{a}$. edição do Standard Methods for the Examination of Dairy Products (A.P.H.A., 1972).

Investigações feitas por CROSSLEY e JOHNSON (1942), mostraram que a microflora do leite em pó é influenciada pela população inicial do leite, tratamento térmico antes e durante a secagem, condições sanitärias dos equipamentos e contamina ção após a secagem.

Um decréscimo no conteūdo microbiano normalmente ocorre durante armazenamentos prolongados do leite em pó, com a taxa de morte sendo influenciada pela umidade do produto, temperatura de armazenamento e tipo de organismos presentes (CROSSLEY e JOHNSON, 1942).

NAGUIB et alii (1972), identificaram os organismos predominantes isolados das contagens totais em placas, para leite em pó, como: Estreptococos, Micrococos, Microbactérias, Sarcina e Bacilos, formadores de esporos. 


\section{2 - Coliformes}

Além de Escherichia coli que é proveniente do trato intestinal, frequentemente incluem-se os seguintes microrga nismos entre os coliformes: Klebsiella, Aerobacter, Salmo nella e Shigella (JAWETz et alii, 1970). Segundo os mesmos au tores, os organismos coliformes mostram-se patogênicos, somente, quando alcançam tecidos fora do trato intestinal, particularmente o trato urinārio, o trato biliar, o peritônio ou as meninges, causando inflamação nestes locais.

ASHTON (1950), verificou que microrganismos do grupo coliforme podem se desenvolver à temperaturas de refrigeração, isto $\bar{e}, 4,5-109 \mathrm{C}$. Segundo o mesmo autor, temperaturas de incubação de 22 e $309 \mathrm{C}$ parecem ser mais favoráveis ao desenvol vimento de coliformes em leite, enquanto que a $379 \mathrm{C}$ o cresci mento é ligeiramente retardado.

Existem dois tipos de $E$. coli enteropatogênica capazes de causar desarranjos de origem alimentar: invasivos e enterotoxinogênicos (FRANK et alii, 1978). Dificuldades tem sido encontradas, tanto para se estimar a incidência de doen ças produzidas por E. coli enteropatogênica, devido a difi culdade do diagnóstico da doença (SACK, 1975), como também para se detectar a presença desse microrganismo em alimentos, em razão dos problemas no isolamento dos organimos (MEHLMAN et alii, 1974) e na determinação da patogenicidade dos isolados 
(MEHLMAN et alii, 1976).

o número de E. coli enteropatogênica necessārio pa ra causar doença, é de $10^{6}$ à $10^{8}$ células para os tipos invasi vos e $10^{8}$ à $10^{9}$ células para os tipos enterotoxinogênicos (MEHLMAN et ali $i, 1976$ ).

Infecções intestinais associadas com a presença de E. coli em alimentos tem recentemente se tornado problema de saúde püblica (MARIER et alii, 1973 e MEHLMAN et alii, 1976), embora $E$. coli enteropatogênica tenha sido mais frequentemen te associada com diarréias infantis em enfermarias (RYDER et alii, 1976).

A presença de $E$. coli enteropatogênica em alguns de rivados do leite, pode ser um problema importante de saúde pública, como evidenciado por um surto em 1971 de gastroenteri tis associadas com queijo camembert (MARIER et ali $i, 1973$ ).

E. coli enteropatogênica tem capacidade de crescer durante a elaboração de queijos moles e semi-moles e de permanecer no produto maturado (FRANK et alii, 1977 e FRANK et alii, 1978), assim como crescer no produto maturado à tempera turas de refrigeração (FANTASIA et alii, 1975).

FRANK et alii (1977), correlacionaram a presença de coliformes fecais em alimentos com a ocorrência de $E$. coli en teropatogênica, o que foi demonstrado no trabalho de FRANK e MARTH (1978). 
A presença de coliformes em queijos, normalmente significa präticas de elaboração inadequadas sob o ponto de vista sanitärio (YALE, 1943 e ERNSTROM, 1954), embora a ocorrência de coliformes fecais em produtos de leite pasteurizado seja sazo nal, com maiores números aparecendo nos meses de verão (JONES et alii, 1967).

A deteção de bactérias coliformes na manteiga é im portante como controle bacteriológico, tanto do ponto de vista higiênico, como da conservação do produto, uma vez que esses mi crorganismos podem causar deterioraçoes no sabor e aroma da man teiga. THOMSON (1950), relacionou a presença de A. aerogenes com o aparecimento de cheiro de estábulo no produto. 0 mesmo autor estabeleceu que organismos coliformes podem ser indicadores das condições de processamento e sua presença na manteiga significa que falhas estão ocorrendo em algum estágio. Ainda segundo THOMSON (1950), para a completa destruição de tais mi crorganismos a temperatura de pasteurização do creme deve ser superior a $85 \% \mathrm{C}$. Desta forma, provado que a pasteurização é efetiva, a presença de coliformes $\vec{e}$ usualmente devido à falta de limpeza dos equipamentos, ou recontaminação por falhas no ma nuseio do produto (THOMSON, 1950). 
Esses microrganismos produzem enterotoxinas classificadas nos seguintes tipos: A, B, C, D, E F (BERgDoll, 1969). Podem ser causadores de nảuseas, salivação, vômitos, diarréias, cólicas abdominais, desidratação, prostração e excessiva transpiração. Febre normalmente não ocorre. Estes sin tomas tem pequena duração (não mais que $1-2$ dias), (BRYAN, $1973)$.

As principais fontes de tais microrganismos são: des cargas nasais e da garganta, mãos e pele, cortes infeccionados, ferimentos, fezes, etc... e assim chegam aos alimentos por falta de cuidados higiênicos no manuseio (BRYAN, 1973).

os Staphyzococcus patogênicos são geralmente hemolíticos e coagulam o plasma sanguíneo. Alguns representantes des te gênero fazem parte da flora normal da pele e mucosas do homem, enquanto outros provocam supurações, formação de abcessos, värias infecções piogênicas e, muitas vezes, septicemias fatais (JAWETZ et alii, 1970).

0 tipo mais frequente de intoxicação alimentar é causado pelas enterotoxinas termoestáveis produzidas por certas es pécies de Staphyzococcus. As enterotoxinas são frequentemente produzidas quando tais microrganismos crescem em alimentos ricos em carboidratos (JAWETZ et alii, 1970). 
A maioria dos Staphyzococcus patogênicos ao homem produz coagulase, uma substância (proteína) que age como enzima capaz de coagular o plasma oxalatado ou citratado, em presença de um fator que existe na maioria dos soros sanguíneos. Este fator sêrico reage com a coagulase, para provocar o aparecimento da atividade da esterase e ação coagulante, de uma maneira similar à ativação de pró-trombina para trombina (JAWETZ et alii, $1970)$

A habilidade de Staphylococcus coagulase negativos produzirem enterotoxina não foi ainda determinada. Entretanto, ba seado em alguns estudos (MINOR e MARTH, 1972 ; RAYMAN et alii, 1975 e SPERBER e TATINI, 1975), pode-se esperar que alguns sta phylococcus coagulase negativos produzam toxina.

Segundo TROLLER (1976), os ótimos de temperatura para produção de toxina e crescimento estão entre 35 e $39 \% \mathrm{C}$. A temperatura minima para o crescimento é $79 \mathrm{C}$ e a máxima 489C. A produção de enterotoxina ocorre entre 10 e $450 \mathrm{C}$.

Embora ocorram variações nos diferentes "strains", o pH minimo para o crescimento de Staphylococcus $\vec{e} 4,6-4,7$, de pendendo do ácido usado para ajustar o pH (MINOR e MARTH, 1972).

0 valor máximo de $\mathrm{pH}$ para o crescimento és provavel mente, 9,5-9,8, embora a produção de enterotoxina normalmente não ocorra com pH superior a 9,0 e se reduz para $50 \%$ à pH igual a 8,0 . $\overline{\mathrm{A}} \mathrm{pH} 5,0$ ou menos, pouca ou nenhuma toxina é produzida. 0 pH ótimo para produção de enterotoxinas B e c é 6,8 , enquan 
to que a sintese de enterotoxina A ocorre em maior proporção com pH entre 5,3 e 6,8 (TROLLER, 1976).

váxios casos de intoxicações alimentares, provenientes da ingestão de queijos contaminados com Staphyzococcus, foram relatados na 1 iteratura por HENDRICKS et a $i$ i (1959).

MARKUS e SILVERMAN (1968), demonstraram que as enterotoxinas sấo produzidas na ültima parte da fase exponencial de crescimentor o que concorda com os trabalhos de MORSE et alii (1969), que mostraram que a produção de enterotoxinas, ocorre en tre a fase exponencial e a fase estacionária.

Embora a intoxicação causada por este organismo se caracterize por baixíssima mortalidade e período relativamente cur to de duração, a frequência dos casos e a severidade dos sinto mas, fazem da intoxicação estafilocócica, uma importante doença em mitos tipos de alimentos (TROLLER, 1976).

Até alguns anos atrás, creme e manteiga, particularmen te o ültimo, não eram considerados veículos de enterotoxina esta filocơcica. A Foodborne Surveillance Unit of the National Cen ter for Disease Control (1970), não havia mencionado nenhum caso de Intoxicação alimentar por S. aureus em manteiga até 1970 , quando 24 pessoas foram atingidas.

Segundo MINOR e MARTH (1972), o creme usado para fabri cação da manteiga pode suportar crescimento de $S$. aureus e pro dução de enterotoxina A, se for estocado à temperaturas eleva das ou deixado por longos periodos à baixas temperaturas. 
Provavelmente o crescimento de Staphylococcus é maior quando a manteiga contém menos que $1,5 \%$ de sal. Tal organismo pode sobreviver na manteiga com mais que $1,5 \%$ de sal, mas a sobrevivência é acentuadamente menor à baixas temperaturas (MINOR e MARTH, 1972).

BERGDOLL (1970), acredita que menos que um micrograma de enterotoxina $A$, pode provocar sintomas de intoxicaçäo estafi locöcica alimentar no ser humano.

Grande número de células vegetativas e mesmo enterotoxinas, podem ser transferidas aos alimentos no manuseio ou pelas superficies dos equipamentos.

Aquecimento é, provavelmente, a técnica mais comumente usada paradestruir Staphylococcus e para inativação ou redução da potência da toxina. o valor $z$ (número de graus necessários para provocar uma mudança de dez vezes no valor D), oscila entre 5 e $69 \mathrm{C}$ e os valores D 60 (tempo à 609C requerido para produzir uma redução de $90 \%$ na contagem das células) são usualmente de 3 a 5 minutos (TROLLER, 1976).

De acordo com os resultados de HEINEMANN (1957), o tem po de destruição térmica de Staphylococcus no leite é de 1,9 minutos à $65 \% \mathrm{C}$.

Staphyzococcus são também susceptiveis aos efeitos bactericidas dos compostos quaternārios de anónia. Esta é a razão de aplicações desses agentes sanificantes em equipamentos utilizados no processamento de alimentos (TROLLER, 1976). 
Um dos aspectos relativos ao crescimento de Staphyzococcus é sua habilidade de crescer em baixos níveis de atividade de água (aw) . A aw mínima para crescimento nos meios utiliza dos em laboratório é aproxidamente 0,86 (SCOTT, 1953 e TROLLER, 1976).

Outro fator limitante de crescimento é a inibição por outros organismos. De uma maneira geral, $S$. aureus, não è um bom competidor e assim é facilmente suprimido por outros organis mos nos alimentos. As razóes desse efeito competitivo podem ser resultado da produção de substâncias inibidoras, competição por nutrientes e alteração em vários fatores de crescimento, levan do-os a níveis desfavoräveis (TROLLER, 1976). Segundo o mesmo autor, microbiologistas em laticínios hä muito tem concluído que culturas iniciadoras são essenciais para prevenir o crescimento de S. aureus durante a elaboração de queijos. Bactérias láticas são as mais importantes iniciadoras que suprimem o crescimento de $S$. aureus, na fabricação de queijos.

DONNELLY et alii (1968), observaram que Staphylococ cus crescem muito pouco em leite cru com altas contagens bacterianas, mas prosperam e produzem enterotoxina em leite pasteuri$z$ ado.

A natureza da atmosfera pode também controlar o cresci mento e produção de enterotoxina. Staphylococcus crescem bem nos meios usados em laboratörio, tanto em condições aeröbicas co mo anaeróbicas, entretanto, a produção de toxina normalmente é 
reduzida em condições anaeróbicas. Em alimentos, uma situação parecida acontece: crescimento formação de toxina podem ocorrer sob condif̧öes anaeróbicas, mas se processam melhor na presen ça de oxigênio.

As contagens de $S$, aureus para produção de enterotoxina devem ser bastante altas: $10^{7}-10^{8}$ células por grama de alimento (TROLLER, 1976 ).

Outros fatores que controlam crescimento e produção de toxina são: complementos nutricionais do meio, pH, temperatu ra, tamanho e tipo do inóculo e o efeito de organismos competido res.

Na indūstria de queijos, um rápido tratamento térmico, à 659C, destrói todos os Staphylococcus naturalmente presen tes no leite. Portanto, leite e seus derivados, desde que ade quadamente tratados termicamente, devem ser livres de um nümero significante desses microrganismos (HEINEMANN, 1957). Assim, o perigo de intoxicação associado com a presença de Staphylococcus em queijos, pode ser considerado reduzido, pelo uso de tratamento tërmico do leite para elaboração de queijos. Uma estreita correlação tem sido observada entre a contagem total inicial do leite e a extensão da multiplicaçäo de Staphylococcus. Isso es tá de acordo com as descobertas de GIBSON e MALLECK (1957), que mostraram que Staphyzococcus à baixas temperaturas $(10-209 \mathrm{C})$, podem crescer ativamente, somente quando a contagem total de bac tërias for baixa. 
TAKAHASHI e JOHNS (1959), sugeriram que uma pronta refrigeração do leite após a ordenha e tratamento térmico antes da elaboração do queijo, diminuem o risco de saúde püblica, associa do com a presença de StaphyZococcus em queijos. Esses autores mostraram também que o soro do leite contém muito pouco StaplyZococcus, sugerindo que a maioria deles fica presa no coágulo. A contagem de Staphylococcus em queijos decresce gradualmente durante a cura e o armazenamento. Ainda no trabalho de TAKAHASHI e JOHNS (1959), ficou evidenciado que nas épocas quentes, con tagens mais elevadas são obtidas.

Um total controle da contaminação de alimentos por Stá phylococcus pode ser difícil de se conseguir, porém, uma sanifi cação efetiva das superfícies dos equipamentos e aceitáveis práticas higiênicas como: frequente e correta lavagem das mãos, re moção de pessoas com doenças respiratörias das áreas de contato com o produto, podem aliviar este problema (TROLLER, 1976).

\section{4 - Salmonelia}

As Salmonellas podem produzir três tipos de doenças, embora sejam frequentes as formas mistas:

A - Febres intestinais: tifóide (S. typhi) e paratifóide (S. paratyphi): As lesões mais destacadas são hiperplasia e necrose do tecido linfóide (por exemplo nas Placas de Peyer), ne- 
crose focal do fígado, inflamação da vesícula biliar e ocasional mente de outros locais, como periósteo e pulmões.

B - Septicemias.

C - Gastrenteritis (denominadas frequentemente de intoxicações alimentares.

Ainda podem causar diarréia, dores abdominais, vômitos, desidratação,prostração e anorexia. A duração de tais sintomas é de vārios dias.

- gênero Salmonelza, enquadrado na família Enterobacteriaceae, é composto por mais de 1.400 serotipos. Todas as espécies são potencialmente patogênicas para o homem, animais ou para ambos (EDWARDS e GALTON, 1967).

Embora a recuperação seja normalmente rápida, algumas complicações podem aparecer em crianças, pessoas idosas e nessoas nas quais a infecção se espalhe no intestino para outras par tes do corpo, resultando em sérios problemas e mesmo em morte (FAGERBERG e AVENS, 1976). Segundo os mesmos autores, Salmone 1 las são bem distribuídas e aparecem em grande variedade de alimentos e em ingredientes de alimentos, causando um grande proble ma na indūstria alimentícia.

Alimentos contendo Salmonelza não devem ser vendidos, pois, de acordo com House Committee on Interstate and Foreign Commerce and the Senate Committee on Labor and Public Welfare (1973), são adulterados por conterem microrganismos danosos ou 
patogênicos.

As fontes contaminantes de alimentos envolvidas constituem principalmente de fezes de animais domésticos,ou não, e do pröprio homem. Além do leite, outros alimentos, como: ovos, carnes, etc., podem conter tais microrganismos (BRYAN, 1973)。

GOEPFERT et alii (1968), encontraram que para uma dimi nuição significativa no número de Salmonella em queijo ched dar, um periodo de 10 a 12 semanas à $139 \mathrm{C}$ deve ser verificado ou de 14 a 16 semanas à $7,50 \mathrm{C}$, no entanto, muitos queijos são consumidos depois de curtos períodos de maturação (às vezes somente dias), o que pode se constituir numa fonte de contaminação por Salmonelza. Por outro lado, desde que esses produtos sejam fabricados com leite adequadamente pasteurizado, a presença de Salmonelza indica contaminação por fontes externas, ou seja, re contaminação (REOGH, 1971).

Numerosas técnicas para isolamento de Salmonelza tem sido propostas para alimentos, mas nenhum método em particular mostrou ser melhor que todos os outros. A maioria dos métodos envolve pré-enriquecimento, enriquecimento, plaqueamento seletivo, testes bioquímicos e serológicos. 0 enriquecimento estimula - crescimento e a multiplicação de Salmonella, enquanto que ou tros organismos gram negativos, como: Coliformes, Proteus, Pseudomonas, são suprimidos ou inibidos (FAgERBERg e AVENS, 1976). 
Métodos para isolamento de Salmonezla foram primeira mente desenvolvidos para espëcimes clínicos, devido à larga distribuição das doenças animais e humanas (GALTON et alii, 1968).

Mais tarde, quando alimentos tornaram-se evidentes como um importante fator nas principais infecções por Salmone 2 za tentou-se o desenvolvimento de métodos que fossem satisfatórios tanto para amostras clínicas como alimentícias. Foi encontrado que estes métodos não eram sempre efetivos na detecção de Salmo nezza em alimentos e, de fato, alguns dos meios eram tóxicos aos organismos (HARGROVE et alii, 1971).

Nenhum procedimento ideal foi ainda recomendado para isolamento de todos os serotipos de Salmonelza em todos os ti pos de alimentos. Muitas variáveis tem sido estudadas nas anā1ises de Salmonelza; algumas são controläveis, outras não. Essas variáveis incluem: tipo de enriquecimento, nümero de com petidores, serotipos de Salmonelza, tipo de amostra e tempo e temperatura de incubação (FAGERBERG e AVENS, 1976).

Atualmente as modificações introduzidas para os meios de enriquecimento propostas pelo Food and Drug Administration's (FDA's) Bacteriological Analytical Manual (1972), pela National Academy of Sciences (1971) e pela Association of Official Analytical Chemists (1970), são as mais recomendadas para o iso lamento de Salmonella em alimentos. 


\section{5 - Bactérias Proteoliticas}

A hidrölise das proteínas do leite por microrganismos é acompanhada pela produção de um sabor amargo devido a forma ção de polipeptídeos. Essa protéolise é favorecida por armazenamento à baixas temperaturas; pela destruição das bactérias là ticas e outros produtores de äcido, pelo calor. A proteólise da caseína no leite e seus derivados por certas bactérias, como: Pseudomonas, Flavobacterium e Alcaligenes, frequentemente resul ta na obtenção de um produto com sabor e aroma alterados (Fos TER et alii, 1957 ; MICKELSON et ali $i, 1967$; CHUNG e CANNON, 1971 e MORENO e KOSIKOWSKI, 1973).

Bactérıas psicrotróficas são dificilmente excluídas do leite cru e assim podem crescer e produzir enzimas proteoliticas durante armazenamento em refrigeração do mesmo (ADAMS et alii, $1975)$.

Desenvolvimento de sabor amargo e coagulação ou gelati nização no leite esterilizado ê comum e pode ser causada por pró teases termo-resistentes (SAMUELSSON e HOLM, 1966). Segundo ADAMS et alii (1975), a maioria das amostras de leite cru pare ce conter proteases termo-resistentes ou bactérias capazes de produzí-1ase, aparentemente, grandes populações de psicrotróficos não são requeridas para a produção de significante protease termo-resistente.

A resistência das proteases produzidas por organismos psicrotróficos, sugere que sua destruição pelo calor é impraticá 
vel. Um tratamento térmico capaz de destruir uma significante taxa de protease, pode ser muito prejudicial às características organoléticas do leite (ADAMS et a $i i i, 1975$ ). Ainda segundo ADAMS et alii (1975), a concentração de caseína e pH do leite,pa recem ser ótimos para a atividade da protease e embora o ótimo de temperatura seja $450 \mathrm{C}$, a protease se mostra bastante ativa à temperatura ambiente (250C). De acordo com os mesmos autores proteases termo-resistentes produzidas no leite cru, podem levar à deterioração de outros produtos do leite e afetar a quali dade de alimentos elaborados com leite e seus derivados.

Inativação de proteases termo-resistentes pelo uso de baixas temperaturas pode ser aplicada antes ou depois da esteri lização. 0 tratamento realizado com melhores resultados foi 559C por uma hora ou menos. Tratamentos com tempo superior à uma hora podem continuar destruindo protease numa taxa baixa, mas alterações das proteínas do soro podem ocorrer (HARLAND et $a$ iii, 1952).

VAN der ZANT e NELSON (1953), encontraram que uma enzima endocelular de Streptococcus lactis causa diferentes graus de proteólise da alfa, beta e gama caseína à diferentes va lores de $\mathrm{pH}$, enquanto que POZNANSKY et ali $i$ (1965), encontra ram enzimas intercelulares de Micrococcus caseolyticum degradando com eficiência a alfa caseína.

PURSCHEL e POLLACK (1972), mostraram que a maioria das bactérias psicrotróficas atacam beta caseína preferencial - 
mente à alfa caseína, enquanto que KIURU et alii (1971) e YANAGIYA et alii (1973), mostraram que enzimas proteoliticas produzidas por Pseudomonas e Flavobacterium spp, degradam igualmente alfa e beta caseína.

MAXERHOFER et alii (1973), mostraram que $P$. fluorescens $\mathrm{P} 26$, produz uma protease que requer $1209 \mathrm{C}$ por nove minu tos para perda de $90 \%$ de sua atividade.

\section{6 - Bactërias Lipoliticas}

Espécies de bactérias formadoras de lipase são encontradas em muitos gêneros, como por exemplo: Pseudomonas, Achromobacter, Alcaligenes, Micrococcus e outros (OVERCAST e SKEAN, 1959).

As bactérias lipolíticas na sua maior parte são aeröbicas ou facultativas, proteolíticas e não produtoras de äcido. A ação dessas bactérias é particularmente importante em cremes, manteigas e queijos, durante períodos extensos de refrigeração. Bactérias lipolíticas frequentemente são psicrotróficas e isso pode se constituir num duplo problema em relação aos defeitos que causam nos produtos acima citados.

ANDERSON e HARDENBERGH (1932), estudaram a deterioração de cremes e manteiga refrigerados, pelo organismo Achromobacter. Durante a deterioração, a ünica mudança bioquímica foi a hidrólise da gordura, o que acarretou o desenvolvimento de 
sabor e aroma amargos.

HAMMER e COLLINS (1934), encontraram que creme cru sem sal não pasteurizado, deixado sete dias à $60 \mathrm{C}$, frequentemente desenvolve rancidez e contém grande número de bactérias lipolítí cas .

THOMAS (1958), concluiu que Pseudomonas fluorescens e Pseudomonas fragi, ambos conhecidos como microrganismos que cres cem bem à 5ọ, podem ser os organismos mais comuns responsáveis pela rancidez que ocorre na manteiga.

DAVIS (1951), acreditava que o gosto amargo produzido no leite deixado à baixa temperatura, era de preferência resulta do da degradação da gordura, do que à formação de peptonas.

Pelos resultados obtidos no trabalho de OVERCAST e SKEAN (1959), nota-se que culturas que crescem bem no leite à $4 \pm 19 \mathrm{C}$, como Pseudomonas, aumentam a quantidade de ácidos gra xos livres no leite. Tal aumento, $\vec{e}$ atribuído somente à ação lí politica dos microrganismos, jā que não ocorreu similar aumento nas amostras controles, ou nas amostras com pouco crescimento. Rancidez e sabor amargo, são defeitos predominantemente desenvol vidos em amostras de leite onde ocorre grande crescimento de organismos lipoliticos (OVERCAST e SKEAN, 1959).

De acordo com MOUREY e KILBERTUS (1976), embora verdadeira a atividade da lipase, ela è às vezes, confundida com a atividade da esterase, porém pode ser detectada realmente pelo $\underline{u}$ so de tributirina como substrato, pois para bactérias há boa cor 
relação entre a atividade da tributirinase e o poder lipolítico. SHAHANI (1974), relacionou alguns tipos de lipases microbianas, com espécies de bactérias dos gêneros Pseudomonas, Achromobacter e Staphylococcus, e uma alta incidência de atividade lipolítica, entre as bactérias psicrotróficas, gram negati vas, em leite cru, foi encontrada por LAW et alii (1976), em strains de Pseudomonas fluorescens e $P$. fragi, sendo que as lipases produzidas por todos os strains lipoliticos permaneceram ativas ou parcialmente ativas depois de aquecimento à 63oc por 30 minutos.

PINHEIRO et alii (1965), mostraram que lipases extrace lulares de bactērias psicrotróficas no leite cru (Pseudomonas e Alcaligenes spp) são resistentes à pasteurização, embora esta mate as células vegetativas. Tais enzimas subsequentemente causam excessiva lipólise e rancidez no creme, na manteiga e nos queijos .

Alguns produtos de leite, como: cremes pasteurizados, creme para elaboração de manteiga, leite em pó integral, etc. es tão sujeitos à vārios tratamentos térmicos abaixo de $1000 \mathrm{C}$ e as sim, são susceptíveis à deterioração pela ação de lipases no armazenamento (LAW et alii, 1976).

O trabalho de NASHIF e NELSON (1953), mostrou que a li pase produzida por $P$. fragi requer vinte minutos à 99oC para sua completa destruição.

Queijos feitos de leites nos quais bastonetes, gram ne gativos, lipoliticos, tenham se multiplicado atingindo $10^{7} \operatorname{colo}-$ 
nias por ml, tornam-se rançosos depois de quatro meses, mesmo que os organismos tenham sidomortos pela pasteurização. A rancidez se caracteriza por um gosto amargo e aroma de sabão em queijos que apresentam concentrações de àcidos graxos 1ivres, 3 a 10 vezes maiores que nos elaborados de leites com baixas contagens de bastonetes, gram negativos, lipoliticos (LAW et alii, 1976). De acordo com os mesmos autores, desde que altas contagens de psicrotróficos no leite cru são requeridas para produzir rancidez em queijos, contagens menores que $10^{6}$ por ml tem pequena influência no sabor e aroma do queijo cheddar, desenvolvidos até que o mesmo esteja maturado (14 meses)..E, no entanto, impor tante lembrar que como o defeito em queijos é causado por lipa ses extracelulares, não importa que as contagens sejam baixas, se suficiente 1 ipase estiver presente.

Segundo FRANKLIN e SHARPE (1963), a temperatura de armazenamento e condições do próprio queijo, tais como: pH e teor salino, afetam a multiplicação e atividade metabólica das bactérias lipolíticas, assim como o desenvolvimento do ranço, jā que a hidrólise da gordura è acentuadamente aumentada com o aumento do $\mathrm{pH}$ e da temperatura.

\section{7 - Bactérias Psicrotróficas}

o termo psicrotröfico é usado na $13^{\text {a }}$ edição do standard Methods for the Examination of Dairy Products (A.P.H.A., 
1972), para indicar os microrganismos que são capazes de formar colônias visiveis em nutriente agar incubado à $70 \mathrm{C}$ por 10 dias. Há mais ou menos uma dééada atrás, psicrotróficos no leite eram chamados psicrófilos e afirmava-se que eram destruídos numa pasteurização bem feita (SEKHAR, 1946 ; ROGICK e BURG WALD, 1952 ; ANDREWS e KAUFFMAN, 1953 ; A. P. H. A., 1960 ; WIT TER， 1961).

EDDY (1960), sugeriu que o termo psicrotröfico fosse usado para indicar os microrganismos, que são capazes de cres cer à baixas temperaturas.

Normalmente as práticas executadas na indústria de la ticinios utilizam grandes volumes de leite cru que permanecem armazenados à temperaturas de refrigeração por longos períodos, durante os quais as bactérias psicrotröficas podem crescer, cau sando mudanças indesejáveis no leite e seus derivados (ANDREY e FRAZIER, 1959 e MORSE et alii, 1968). A presença de organismos psicrotróficos não somente indica baixa qualidade do leite, como também insatisfatōrias condições sanitárias no processamen to.

Os microrganismos psicrotróficos, podem causar muitos danos no leite e seus derivados, quando estocados em temperaturas que vão de 1 -7ọC (ELLIKER et ali $i, 1964$; THOMAS et ali $i$, 1966 ; FORD e BABEL, 1969 e LUCK, 1972).

BABEL (1953), encontrou que a acidez da gordura do leite, aumenta lentamente quando este é mantido à $4,40 \mathrm{C}$, as 
aumenta rapidamente quando hä uma elevação marcante no número de organismos psicrotröficos.

MARTH e FRAZIER (1957), mostraram que os psicrotrófi cos predominantes em leite cru comercial são: Pseudomonas, Achromobacter e Flavobacterium.

No trabalho de ANDREY e FRAZIER (1959), bactërias psicrotróficas foram isoladas de 174 amostras de leite tipo A. 0s isolados obtidos foram identificados e a maioria pertenceu aos gêneros: Aerobacter, Alcaligenes, Arthrobacter, Flavobacterium, Micrococcus e Pseudomonas. Foi ainda observado que o pastoreio extensivo ou o tratamento em confinamento, tem grande influência no número de psicrotrōficos. Assin, Arthrobacter, seguido por Pseudomonas e Micrococcus, predominaram quando as vacas estavam confinadas e Flavobacterium e Alcaligenes, quando em pastoreio extensivo.

0 número de organismos psicrotróficos no leite è frequentemente usado para avaliaf̧ão da qualidade do produto. 0 pro cedimento convencional para contagens de psicrotróficos requer 10 dias de incubação $\bar{a} 79 \mathrm{C}$, entrentanto, oliveria e PARMElEE (1976), mostraram que as bactérias psicrotróficas do leite crescem bem à $219 \mathrm{C}$, enquanto que as mesōfilas crescembastante lentamente à esta temperatura. Eles encontraram que incubação à $219 \mathrm{C}$ por 25 horas é equivalente à incubação à $79 \mathrm{C}$ por 10 dias. Segundo alguns autores (WITTER, 1961 e THOMAS e DRUCE, 1969), organismos psicrotrófices, não sobrevivem à pasteurização 
e assim, sua presença em leites processados è devido à contaminação após a pasteurização. Alguns pesquisadores, entretanto, tem mostrado que pequeno número de organismos psicrotróficos po de sobreviver à pasteurização e esterilização (GROSSKOPF e HAR PER, 1969 ; WATROUS et ali $i, 1971$ e PATEL e BLANKENAGEL, 1972). Mas, THOMAS e DRUCE (1969) e BHADSAVLE et a $i$ i (1972), mostraram que leite pasteurizado deve ser estocado à $79 \mathrm{C}$ pelo menos uma semana, antes dos psicrotróficos resistentes ao calor, poderem ser detectados (tempo necessário para o reparo das células dani ficadas ).

JUFFS e BABEL (1975), utilizaram vārias culturas de bactérias láticas afim de conseguirem inibição de bactérias ps crotróficas e verificaram ser Leuconostoc cremoris a mais efe tiva. Por outro lado, OVERCAST e ATMARAM (1974), mostraram que o crescimento excessivo das bactérias gram negativas no leite antes do processamento, pode ter um efeito estimulante no crescimento subsequente de organismos psicrotróficos formadores de esporos.

Bactérias psicrotróficas dos gêneros: Pseudomonas, $A$ cinetobacter, Flavobacterium e Alcaligenes, podem produzir enzimas, como lipases e proteinases, as quais não são inativa das pela pasteurização (COUSINS et alii, 1977). Essas bactérias e outras pertencentes aos gêneros Citrobacter e Bacizzus, são também produtoras de fosfolipase C . Existem poucas referên cias na literatura sobre os efeitos da fosfolipase C em leite 
e em outros alimentos, porém, o trabalho de FoX et alii (1976), mostrou que organismos psicrotróficos produtores de fosfolipase $C$, frequentemente estão presentes em grandes nümeros em leites deteriorados.

\section{$3.8-$ Bactérias Termöfilas}

Deverse considerar o fato de que quando leite com alta população inicial de organismos termo-resistentes é desidratado, eles podem sobreviver em números suficientes para repre sentar um risco na qualidade do produto quando o mesmo for reconstituído e usado em alimentos (THOMPSON et ali $i, 1978$ ).

A presença de microrganismos no leite em pó, vem confirmar o trabalho de KEOGH (1971), que mostrou que o tratamento térmico que o leite recebe durante a secagem não elimina todas as bactérias e a maioria dos organismos presentes no leite em pö são formadores de esporos ou termo-resistentes, como: $M i$ crococcus e outras microbactérias.

Segundo JONES e LANGLOIS (1977), em leite e derivados, ocorrem números mais ou menos parecidos de termófilos e esporulados, mostrando que provavelmente os termófilos encontrados são produtores de esporos. 


\section{$3.9-$ Enterococos}

os enterococos são membros do gênero Streptococcus que consistem de cocos gram positivos, produzindo cadeias curtas ou longas e que diferem da maioria dos outros cocos gram positivos por serem catalase negativos.

Apesar da existência de certas discussões sobre quais as espëcies de Streptococcus que deveriam ser incluidas no ter mo Enterococos, parece ser aceito que os enterococos são membros dos Estreptococos do grupo serológico D. Este grupo consiste de quatro espécies distintas:

Streptococcus faecalis $\left[\begin{array}{l}\text { var. } \\ \text { var. } i q u\end{array}\right.$
Streptococcus faecium var. durans
Streptococcus bovis
Streptococcus equinus

Os enterococos de maior importância em alimentos pertencem as espécies: $S$. faecaíis e $S$. faecium. Em relação aos padrões para enterococos atualmente em uso, admite-se que em geral não deven existir em mais que 1.000 organismos por grama de alimento (A.P.H.A., 1967).

Espécies de enterococos consideradas termodúricas, são capazes de crescer à baixas temperaturas (JENSEN et a $i$ i, 1975 e TINUOYE e HARMON, 1975). 
S. faecalis var. Ziquefaciens, é considerada uma bactéria que altera o sabor e a qualidade do leite, sendo portanto, indesejável em tal produto (WASHAM et ali $i, 1977$ ).

\subsection{0 - Fungos e Leveduras}

Certos fungos como Penicizlium camemberti e. PenicilZium roqueforti, são necessārios para a maturação dos respectivos queijos, pois suas atividades proteoliticas e lipolíticas são responsáveis pelo sabor e aroma característicos, bem como pela aparência de tais produtos (FOSTER et alii, 1957).

Porém, outros fungos podem ser responsáveis pela deterioração do produto, ou por mudanças indesejáveis que tornam o produto de baixa qualidade e de difícil comercialização. Assim, espécies de Aspergizzus, tem sido encontradas em latas de leite condensado açucarado, onde crescem por um tempo limitado e formam botões. Normalmente, coagulam a caseína do leite (FOS TER et alii, 1957).

Segundo os mesmos autores, espécies de Cladosporium e Alternaria, têm sido encontradas causando discoloração da super fície de manteigas, o que è bastante indesejável.

Geotrichum candidum (antes denominado oospora lactis e Oidium Zactis), oxida o ācido 1ātico do leite e derivados à gás carbônico e ägua e isso rapidamente hidrolisa a gordura do creme da manteiga. Esse fungo, cresce na superficie do creme e queijos 
azedos, como uma firme massa branca. Ele é responsável pela pro dução de sabores desagradáveis nos derivados do leite. Não é um fungo sacarolítico e sua importância reside em suas característi cas oxidativas e lipolíticas. Ele é destruído pela pasteurização e sua presença no creme pasteurizado e na manteiga é inter pretada como indicador de falhas no processamento ou recontamina ção (FOSTER et alii, 1957).

Segundo BRINDLEY (1954), os fatores que parecem estar envolvidos com a presença de certos fungos e bactérias indesejāveis no queijo, são: controle inadequado da ventilação durante a drenagem e formação da casca, viragens insuficientes do queijo e poucas mudanças das bandagens.

No trabalho de FRYER e SHARPE (1965), uma linhagem de Streptomyces albus, presumivelmente originária do leite cru, foi encontrada em grande nümero em queijos cheddar. 0 nümero de Streptomyces, permaneceu constante, por um período de quatro me ses. A resistência ao calor foi examinada para as células mice1 iais e conidios, usando-se 62,5 e $71,7 \% \mathrm{C}$. As células miceliais não mostraram resistência às temperaturas citadas, sendo $100 \%$ a porcentagem de morte. Os conídios entretanto, foram muito menos afetados depois de duas horas à 62,5 e $3 \%$ permaneceram viáveis depois de 30 minutros à $71,79 \mathrm{C}$.

SHAHANI (1974), relacionou alguns tipos de 1 ipases microbianas, incluindo: espēcies de leveduras dos gêneros Candida e Toruzopsis e espécies de fungos dos gêneros Rhizopus, 
Penicillium, Aspergillus, Geotrichum e Mucor.

De acordo com KOSIROWSKI (1970), uma sö contagem deve ser efetuada para se estimar fungos e leveduras em um alimento, ou seja, ambos devem ser incluídos na mesma contagem.

A presença de fungos e outras evidências visuais ou o 1 fativas de deterioração, são aceitas como causa de rejeição de um produto alimentício (HOBBS e GILBERT, 1974). 
4 - MATERIAL E METODOS

As amostras dos derivados do leite utilizadas neste tra balho, foram adquiridas no comércio local de Piracicaba e conduzidas imediatamente ao laboratório para serem examinadas.

No presente trabalho as seguintes amostras, com três repetições de cada uma, identificadas como A, B e C, foram ana 1 is adas:
A - Queijo Tipo Prato
B - Queijo Tipo Minas Frescal
C - Queijo Tipo Provolone
D - Leite em Pó Integral
E - Leite em Pó Desnatado
F - Manteiga sem Sal
G - Manteiga com Sal 
A amostragem foi feita usando-se um amostrador (trado) para queijos e manteigas, procurando-se tomar pontos bem espar sos da superficie do produto. 0 amostrador foi introduzido por toda a altura da amostra e $50 \mathrm{~g}$ foran tomados para anāiise. Para leite em pó, foram tomadas $50 \mathrm{~g}$ da embalagem comercial. Para cada uma das amostras, os $50 \mathrm{~g}$ foram colocados em liquidificador contendo $450 \mathrm{ml}$ de solução de citrato de sódio (2\%) e batidos por dois minutos. Foram preparadas diluições em sērie utilizando-se ägua peptonada $(0,1 \%)$ estēril.

Para todas as determinaçóes, as contagens das colônias foram realizadas em contador tipo Quebec.

\section{1 - Contagem Total.}

Feita por plaqueamento das diluições em sërie em meio padrão, segundo SHARF (1972). A contagem das colônicas foi efetuada apōs incubação por 43 horas à $329 \mathrm{C}$.

\section{$4.2-$ Coliformes}

A metodologia empregada para contagem e caracterização desse grupo de microrganismos seguiu as especificações do Standard Methods for the Examination of Dairy Products (A.P. H. A., 1972), tendo sido empregado Vermelho Violeta Bile Agar como meio 
seletivo e incubação à $320 \mathrm{C}$ por 48 horas. Para caracterização dos coliformes presentes, dez colónias ao acaso foram retiradas (SHARF, 1972) e colocadas em tubos de ensaio contendo leite tornassolado, sendo incubados à $320 \mathrm{C}$ por 24 horas. Depois de reali zar coloração de Gram para estas culturas, foi feito plaqueamento por estrias em meio Eosina Azul de Metileno incubado à 32 o.C por 24 horas. Em seguida, foram realizados os testes bioquími cos: Produção de Indol, Prova de Vermelho de Metila e Voges Pros krauer, e Utilização de Citrato (IMViC), para diferenciação de Escherichia coli e Aerobacter aerogenes. A enumeração de coli formes fecais, foi feita com caldo $E$. coli em tubos de ensaios contendo tubos de Durham invertidos e mantidos em banho maria a $45,59 \mathrm{C}$ por 24 horas.

\section{3 - Staphyzococcus}

Para isolamento e contagem desses organismos, placas com Nutriente Agar, Extrato de Levedura $(0,3 \%)$ e 7,5\% de cloreto de só dio (DIFCo MANUAL, 1957), inoculadas com diluições em série, foram incubadas à $320 \mathrm{C}$ por 48 horas, sendo feita contagem das colónias depois desse periodo. Das placas contadas, foram retiradas dez colonias ao acaso (SHARF, 1972), as quais foram transferidas para tubos de ensaio com Caldo Nutriente mais $7,5 \%$ de cloreto de sódio e incubados à $320 \mathrm{C}$ por 24 horas. Em seguida, foi feita colo ração de Gram. Para a caracterização de $S$. aureus, foram rea lizados os testes bioquímicos IMViC; plaqueamento por estrias 
de todas as culturas em meio de Baird-Parker com incubação à $350 \mathrm{C}$ por 48 horas e teste para produção de coagulase (Laborato ry Exercices for Food Microbiology, BANWART, 1975).

$4.4-$ Salmonelza

0 isolamento e a identificação de Salmonella, foram feitos segundo as normas do Laboratory Exercices for Food Micro biology (BANWART, 1975). Para o isolamento, 25 g do produto fo ram colocados juntamente com $225 \mathrm{ml}$ de Caldo Selenito Cistina em liquidificador e batidos durante dois minutos, com posterior incubação à 35 ọ por 24 horas (enriquecimento). Em seguida, foi feito plaqueamento, por estrias, nos meios seletivos: Verde Bri 1hante Agar (VBA), com incubação à 350 C por 24 horas, Bismuto Su fito Agar (BSA) com incubação à 350 C por 48 horas e Salmonella Shigelza Agar (SSA) com incubação à 35 o por 24 horas. Depois desse período, colonias típicas de Salmonelza de cada um dos meios seletivos, foram transferidas com agulha de platina, para tubos de ensaio com meio Triple Sugar Iron Agar (TSI) inclinado e incubados à 359 c por 24 horas. A seguir foi feita coloração de Gram. Para a comprovação da presença de Salmonelza, foram realizados os testes bioquímicos descritos no Laboratory Exerci ces for Food Microbiology (BANWART, 1975). 


\section{5 - Proteoliticos}

Placas com meio padrão para contagem total (SHARF, 1972), mais $1 \%$ de leite desnatado esterilizado, inoculadas com diluições em série, foram incubadas à $320 \mathrm{C}$ por 48 horas. Em seguida, foi feita contagem das colônias de proteolíticos (com um halo de proteólise ao redor da colónia), segundo as normas do Standard Methods for the Examination of Dairy Products (A.P.H.A.s 1972).

\section{$4.6-\underline{\text { Lipoliticos }}$}

Placas com meio Azul Espirito Agar, inoculadas com dilui ções em série, foram incubadas à $329 \mathrm{C}$ por cinco dias e depois des se periodo, colônias tipicas de organismos lipoliticos (envoltas por uma zona azul), foram contadas. Laboratory Exercices for Food Microbiology (BANWART, 1975).

\section{7 - Psicrotróficos}

Para esse grupo de microrganismos, tambëm se empregou o meio para contagem total (SHARF, 1972), com incubação à 21 oc por 25 horas (OLIVERIA e PARMELEE, 1976) e 79C por dez dias, de acordo com as recomendações do Standard Methods for the Examination of Dairy Products (A.P.H.A., 1972), sendo a contagem das colónias feita após esse períado. 
$4.8-\underline{\text { Termófilos }}$

0 meio utilizado foi o mesmo empregado para a contagem total (SHARF, 1972), porém com incubação à 550̣ por 48 horas, se gundo as normas do Standard Methods for the Examination of Dairy Products (A.P.H.A., 1972), sendo feita contagem das colônias depois desse período.

\section{$4.9-$ Enterococos}

0 método empregado seguiu as especificações do Laboratory Exercices for Food Microbiology (BANWART, 1975), sendo as placas inoculadas com diluições apropriadas contendo meio KF Streptococcus Agar, incubadas à $32 \% \mathrm{C}$ por 48 horas. Depois desse período as colônias típicas de enterococos (vermelhas), foram contadas.

\subsection{0 - Fungos e Leveduras}

A contagem desses organismas foi feita por plaqueamen to das diluições em série em placas com meio de Malte $(p H=3,5)$ incubadas à $320 \mathrm{C}$ por cinco dias. A primeira contagem foi realizada deppois de três dias de incubação e ambos os microrganismos foram colocados numa só contagem, de acordo com KOSIKOWSKI (1970). 


\subsection{1 - Esporulados Aeröbicos}

$$
\text { Para a contagem desses organismos, } 5 \mathrm{~g} \text { de leite em pó }
$$
de cada amostra foram pesados e diluídos em $45 \mathrm{~m} 1$ de água destilada estēril, com aquecimento de $809 \mathrm{C}$ por dez minutos. Foi realizado plaqueamento em meio padrão para contagem total (SHARF, 1972) com incubação de 32 o por 24 horas, sendo em seguida feita contagem das colonias (Standard Methods for the Examination of the Dairy Products, A.P.H.A., 1972). 
os resultados obtidos nas determinações microbiolögicas para as amostras de derivados do leite utilizadas neste tra balho, encontram-se nas Tabelas 1,2 e 3 . 0 s numeros repre sentam valores médios, ja que todas as determinações foram conduzidas em duplicata.

$5.1-$ Queijos

\section{$5.1 .1-$ Contagem total}

Os resultados obtidos para os três tipos de queijos a nalisados (Tabela 1), variaram de $8,0 \times 10^{6}$ à $2,3 \times 10^{7}$ micror ganismos / g para queijo tipo Prato; de $1,6 \times 10^{8}$ à $2,2 \times 10^{8}$ 
microrganismos / $g$ para queijo tipo Minas Frescal e de $1,0 \times 10^{7}$ à $2,0 \times 10^{7}$ microrganismos / g para queijo tipo Provolone, sendo as maiores contagens para o tipo Minas Frescal, o que era de se esperar devido ao seu alto teor de umidade. As altas contagens encontradas para os queijos Prato e Provolone podem indicar que os mesmos, apresentam alta atividade de ägua, ou que, o período de maturação fora curto, permitindo que um nümero elevado de bac térias 1áticas permaneçam vivas, uma vez que o nümero dessas bac térias em queijos é grandemente afetado pela atividade de água (aw) a qual diminui com o prolongamento da maturação.

\section{$5.1 .2-$ Coliformes}

A Tabela 1 mostra os resultados obtidos tanto para coliformes totais como para coliformes fecais nas amostras analis das, os quais oscilaram de $6,3 \times 10^{2}$ à $2,0 \times 10^{3}$ coliformes totais/g para queijo tipo Prato, de $8,5 \times 10^{4}$ à $1,7 \times 10^{5}$ colifor mes totais/g para queijo tipo Minas Frescal, de $3,0 \times 10^{2}$ à 8,8 $x 10^{2}$ coliformes totais/g para queijo tipo Provolone e de $4,0 \mathrm{x}$ $10^{2}$ à $1,2 \times 10^{3}$ coliformes fecais/g para queijo tipo Prato; de $4,0 \times 10^{4}$ à $1,6 \times 10^{5}$ coliformes fecais/g paraqueijo tipo Minas Frescal, e, para queijo tipo Provolone, ausência completa de co1 iformes fecais nas amostras analisadas. As contagens para $E$. coli, variaram de $4,0 \times 10^{2}$ a $1,1 \times 10^{3} / \mathrm{g}$ para queijo Tipo Pra to, de $2,9 \times 10^{4}$ à $1,6 \times 10^{5} / \mathrm{g}$, para queijo tipo Minas Fres - 
cal e nenhuma das amostras de queijo tipo Provolone analisadas apresentou essa bactéria. Esses resultados estão acima dos padrões estabelecidos pela Comissão Nacional de Normas e Padrões para Alimentos (CNNPA, 1978), que são de $10^{2}$ coliformes fecais/ g para queijo Frescal e 10 coliformes fecais/g para queijo cura do, como é o caso dos queijos tipo Prato e Provolone.

Ess as contagens são também superiores aos padrões estabelecidos pelo Instituto Canadense de Proteção à Saūde (COLLINS-THOMPSON et alii, 1977), que são: $m=5,0 \times 10^{2} / g$ (nível de microrganismos aceitável) e $M=1,5 \times 10^{3} / \mathrm{g}$ (nível de microrganismos não acei tável) para coliformes totais e $m=1,0 \times 10^{2} / \mathrm{g}$ e $M=5,0 \mathrm{x}$ $10^{2} / g$ para coliformes fecais, para queijos feitos de leite pasteurizado. Vêe-se que somente as amostras de queijo tipo Provolo ne se enquadraram nos padrões acima referidos. Os resultados da Tabela 1 mostram que as amostras de queijo tipo Minas Frescal (queijo mole) apresentaram valores acima de $1,6 \times 10^{3}$ coliformes fecais/g, os quais são semelhantes aos encontrados por CollinsTHOMPSON et alii (1977), em queijos de pasta mole. A presença de grande número de coliformes em queijos, normalmente se deve a contaminação após a pasteurização ou à baixa atividade da cultura iniciadora (produtores de àcido), (FRANK et alii, 1977). YALE (1943), DELAY (1947) e ERNSTROM (1954), mostraram que a presença de E. coli em produtos láteos pode ser utilizada como indicador de contaminação após a pasteurização ou à baixa atividade da cultura iniciadora e assim, a constatação da presença de 
E. coli em amostras de queijos tipo Minas Frescal e Prato, demonstra que práticas inadequadas sob o ponto de vista higiênico estão sendo empregadas no processamento de tais produtos.

\section{$5.1 .3-$ StaphyZococcus}

os padrões propostos pela CNNPA (1978), em relação à S. aureus em derivados do leite, são os seguintes: $10^{3} / \mathrm{g}$ para queijo Frescal e $10^{2} / \mathrm{g}$ para queijo curado. Os resultados obtidos para esse microrganismo nas amostras analisadas (Tabela 1), mostraram variações de $2,9 \times 10^{4}$ à $4,4 \times 10^{4}$ microrganismos/g para queijo tipo Prato, de $3,3 \times 10^{5}$ à $3,7 \times 10^{5} \mathrm{microrganismos} / \mathrm{g}$ para queijo tipo Minas Frescal, e para queijo tipo Provolone de $1,2 \times 10^{4}$ à $2,3 \times 10^{4}$ microrganismos/g, sendo bastante superiores nos padrões acima citados. MUSSOI (1974), entretanto, anali sando queijos tipo Lanche e Prato, näo constatou a presença desse microrganismo nesses produtos. Os resultados obtidos são tam bém superiores aos padrões apresentados pelo Instituto Canadense de Proteção à Saūde (COLlins-THOMPSON et alii, 1977), que são: $\mathrm{m}=1,0 \times 10^{2} / \mathrm{g}$ e $M=1,0 \times 10^{3} / \mathrm{g}$ para queijos feitos de 1 eite pasteurizado. A alta incidência de $S$. aureus em queijos, mos tra que a pasteurização do leite não foi adequada, uma vez que 
esse microrganismo é destruído por esse tratamento térmico (TROLLER, 1976).

READ et alii (1963), concluíram que alimentos contendo cerca de $5,0 \times 10^{5}$ Staphylococcus coagulase positivos/g devem ser considerados impróprios ao consumo humano, devido a produção significativa de enterotoxinas. Os nümeros encontrados pa ra esse microrganismo nas amostras de queijo tipo Minas Frescal (Tabela 1) estão bastante próximos dos valores mencionados pelos autores acima, o que leva a crer que as mesmas tambem podem ser consideradas inadequadas ao consumo. 0 grande nümero de $S$. a reus encontrado em queijos pode ser o resultado de baixa ativi dade da cultura iniciadora (produtores de ācido), uma vez que Staphylococcus coagulase positivos, multiplicam-se rapidamente durante a elaboração de queijos, nos quais os organismos produto res de àcidos (bactérias läticas), tenham sido contaminados por fagos (SHARPE et alii, 1962 e REITER, 1964).

\section{1 .4 - Salmonelza}

De acordo com os padröes apresentados pela CNNPA (1978), esse organismo não deve aparecer em $25 \mathrm{~g}$ do produto. No entan to, os resultados da Tabela 1 , mostram que uma das amostras de queijo tipo Minas Frescal e outra de queijo tipo Prato, foram positivas para Salmonelza, o que demonstra que os mesmos não deveriam ser postos à venda, uma vez que estão foradoc 1 imites 
estabelecidos pela Comissão Nacional de Normas e Padrões para A1 imentos, pois se constituem num grande risco de infecção para a população que os consome. A presença de tais microrganismos em alimentos, pode ser correlacionada também com falta de higieniza ção, falhas no tratamento térmico durante o processamento do pro duto elou pós contaminação do mesmo.

\section{1 .5 - Fungos e leveduras}

Os resultados da Tabela 1 para esses microrganismos apresentaram oscilações de $1,5 \times 10^{4}$ à $1,6 \times 10^{5} \mathrm{microrganismos} / \mathrm{g}$ para queijo tipo Prato, de $2,4 \times 10^{3}$ à $7,0 \times 10^{3}$ microrganismos $/$ g para queijo tipo Minas Frescal e para o queijo tipo Provolone de $5,1 \times 10^{4}$ à $5,4 \times 10^{4}$ microrganismos/g. Essas variações são semelhantes àquelas encontradas por Mussol (1974), que foram de $10^{4}$ à $10^{6}$ para queijos tipo Prato e Lanche. Embora não existam padrões nacionais estabelecidos para esses grupos de microrganismos em produtos láteos, é sabido que a presença de fungos $\ddot{e}$ aceita como causa de rejeição de um produto alimentício (HOBBS e GILBERT, 1974). Esses microrganismos normalmente alcançam os alimentos na fase de acondicionamento do produto e também atra vês de contaminações pelos equipamentos durante a elaboração, con trole inadequado da ventilação durante a drenagem e formação da casca, viragens insuficientes do queijo e poucas mudanças das ban dagens (BRINDLEY, 1954 ). 


\section{1 .6 - Psicrotróficos}

Sabe-se que microrganismos psicrotróficos são indesejā veis em produtos láteos, uma vez que podem causar alterações indesejāveis no sabor e aroma desses alimentos (WEICKBACH e LANGLOIS, 1977). As contagens encontradas para esses microrganismos em queijos (Tabela 1), mostram que incubação à $7: C / 10$ dias e a $219 \mathrm{C} / 25$ horas foram equivalentes, como foi demonstrado por OLIVERIA e PARMELEE (1976). A amostra C do queijo tipo Prato não apresentou contagens desses organismos em nenhuma das temperaturas de incubação utilizadas, enquanto que as amostras $A$ e do mesmo tipo de queijo apresentaram variações de $4,0 \times 10^{1}$ a 1,3 $\times 10^{2}$ microrganismos/g, quando incubadas a $79 \mathrm{C} / 10 \mathrm{dias}$ e de $4,5 \times 10^{1} \bar{a} 1,5 \times 10^{2} \mathrm{microrganismos} / \mathrm{g}$, quando incubadas a $219 \mathrm{C} / 25$ horas. Para as amostras de queijo tipo Minas Frescal as variações foram de $2,5 \times 10^{2}$ à $7,9 \times 10^{2} \mathrm{microrganismos} / \mathrm{g}$ pa ra incubação a $790 \mathrm{C} / 10$ dias e de $2,0 \times 10^{2}$ à $8,0 \times 10^{2}$ microrganismos/g para incubação a $219 \mathrm{C} / 25$ horas. Nenhuma das amostras de queijo tipo Provolone analisadas apresentou contagens desses microrganismos em ambos os tipos de incubação empregados. Embora não existam padrões estabelecidos para a presença desses microrganismos em derivados do leite, pode-se concluir que falhas no controle da temperatura de pasteurização possivelmente devem ter ocorrido, uma vez que, a grande maioria dos organismos psi crotróficos é destruída numa pasteurização bem efetuada, como de monstrado por THOMAS e SEKHAR (1946); ROGICK e BURGWALD (1952) 
e ANDREWS e KAUFFMAN (1953).

\section{1 .7 - Termöfilos}

As contagens para esses microrganismos variaram de $1,0 \times 10^{1}$ à $1,7 \times 10^{2}$ microrganismos/g paraqueijo tipo Prato, de $7,2 \times 10^{2}$ à $9,9 \times 10^{2}$ microrganismos/g paraqueijo tipo Provolone e em nenhuma das amostras de queijo tipo Minas Frescal foi constatada a presença desses microrganismos (Tabela 1). Em bora a CNNPA (1978), não estabeleça 1 imites para a presença des ses organismos em leite e derivados, sabe-se que os tratamentos térmicos empregados na elaboração de queijos não são suficien tes para eliminar as bactérias termöfilas e como normalmente elas são formadoras de esporos, estes permanecem no alimento podendo em seguida germinarem e colocarem em risco a qualidade do produto (KEOGH, 1971 ).

\section{$5.1 .8-$ Enterococos}

A Tabela 1 mostra oscilações de $1,2 \times 10^{4}$ à $2,5 \times 10^{4}$ microrganismos/8 para queijo tipo Prato, de $1,3 \times 10^{5}$ à $2,8 \times$ $10^{5}$ microrganismos/g para queijo tipo Minas Frescal e de $2,9 \times$ $10^{4}$ à $7,7 \times 10^{5}$ microrganismos/g para queijo tipo Provolone. Apesar de não existirem padrões nacionais que limitem a presen 
ça desses microrganismos, o valor máximo estabelecido pela American Public Health Association (1967), é de $10^{3}$ enterococos $/ \mathrm{g}$ de alimento. Os resultados obtidos nesse trabalho são bastante superiores ao padrão acima mencionado, o que demonstra a necessidade de se estabelecerem 1 imites para a presença de tais microrganismos em alimentos, uma vez que, além de causarem altera ções no sabor e aroma de leite e derivados (WASHAM et a $i$ i , 1977), podem se constituir em agentes causais de infecções ao homem (BRYAN, 1973).

\subsection{9 - Proteoliticos}

As contagens de proteoliticos (Tabela 1), variaram de $2,6 \times 10^{2}$ à $6,4 \times 10^{2}$ microrganismos/g para queijo tipo Prato, de 4,0 x $10^{4}$ à $7,8 \times 10^{4}$ microrganismos/g paraqueijo tipo Minas Frescal e para queijo tipo Provolone de $2,0 \times 10^{4} \bar{a} 1,2 \times$ $10^{5}$ microrganismos/g. A não existência de padrões para a presença desses microrganismos em derivados do leite, não permitem um julgamento preciso da influência de tais organismos na quali dade dos produtos analisados, mas é importante que o nümero deles seja o mais reduzido possível, pois värios trabalhos já mos traram que proteases produzidas por esses microrganismos alte ram as qualidades dos produtos láteos, tornando-os amargos devi do à formação dẹ polipeptídeos e, portanto, inadequados para o 
consumo (MICKELSON et alii, 1967 ; CHUNG e CANNON, 1971 e MORENO e KOSIKOWSKI, 1973).

\section{$5.1 .10-$ Lipolíticos}

Os nümeros encontrados para esses microrganismos nas amostras analisadas (Tabela 1), mostram variações de $1,0 \times 10^{3}$ à $1,7 \times 10^{3}$ microrganismos/g paraqueijo tipo Prato, de $2,7 \times$ $10^{4}$ à $9,1 \times 10^{4} \mathrm{microrganismos} / \mathrm{g}$ para queijo tipo Minas Frescal e de $2,3 \times 10^{4}$ à $2,4 \times 10^{4}$ microrganismos/g para queijo tipo Pro volone. Os valores elevados encontrados para tais microrganis mos representam um risco em relação a qualidade do alimento, uma vez que as 1 ipases produzidas por tais microrganismos podem causar alterações indesejäveis no sabor e aroma dos queijos. Sabese que uma pasteurização bem feita destroe as células vegetati vas dos organismos lipolíticos e assim, o grande nümero verifica do, deve-se, provavelmente, à contaminação após a pasteurização. Alèm do nümero de células presentes, temos que considerar também o fato de que a pasteurização não elimina as lipases produzidas por muitos organismos lipolíticos e estas, subsequentemente, cau sam excessiva lipólise e rancidez nos queijos (PINHEIRo et alii, 1965). Seria, portanto, interessante que técnicas adequadas fos sem adotadas para reduzir ao mínimo a presença desses microrga nismos em derivados do leite, como é o caso de queijos. 


\section{2 - Leite em Pó}

\section{2 .1 - Contagem total}

Os resultados obtidos para as amostras analisadas (Tabela 2), variaram de $9,2 \times 10^{5}$ a $1,1 \times 10^{6}$ microrganismos/g para leite em pó integral e de $3,2 \times 10^{5}$ à $8,6 \times 10^{5}$ microrganismos $/ g$ para leite em pó desnatado. Esses resultados são superiores aos padrões estabelecidos pela Comissão Nacional de Normas e Padrões para Alimentos (CNNPA, 1978), que são de 5,0 x $10^{4}$ microrganismos/g e estão tambëm acima dos padrões bacterianos estabelecidos pelo American Dry Milk Institute (1973), que permitem no máximo $5,0 \times 10^{4}$ microrganismos $/ g$ para o tipo extra e $1,0 \times 10^{5}$ microrganismos/g para o tipo padrão. Os valores encontrados são semeIhantes aos resultados obtidos por JONES e LANGLOIS (1977), que encontraram $15,6 \%$ das amostras de 1 eite em pö integral e $30,1 \%$ das amostras de leite em pó desnatado, contendo números superiores à $2,0 \times 10^{4} \mathrm{microrganismos} / \mathrm{g}$. Esses resultados elevados indicam possiveis irregularidades durante o processamento e acondi cionamento, ou seja, falhas no controle da temperatura de pasteu rização, sanificação deficiente dos equipamentos envolvidos na elaboração desse produto, ou matéria prima com carga microbiana e 1 evada. 


\section{$5.2 .2-$ Coliformes}

Nenhum organismo do grupo coliforme foi isolado das amostras de leite em pó integral e desnatado (Tabela 2). De acordo com esses resultados esses produtos se enquadram nos padrões da CNNPA (1978) e tambén nos padrōes do American Dry Milk Institute (1973), que são, ausência de coliformes fecais/g e 10 coliformes totais/g de produto, respectivamente.

\section{$5.2 .3-$ Staphyzococcus}

Os padrões propostos pela CNNPA (1978), em relação à S. aureus em leite em pó são de $10 \mathrm{microrganismos} / \mathrm{g}$ de produ to. A ausência de $S$. aureus nas amostras analisadas (Tabela 2), permite o enquadramento desse produto nos padrões acima referidos, o que os torna inócuos do ponto de vista de saūde püblica.

\section{$5.2 .4-$ Salmonezza}

As amostras de leite em pó analisadas não apresenta ram tal organismo em $25 \mathrm{~g}$ do produto. Esses resultados se enquadram nos padrões da CNNPA (1978) e também da Food and Drugs Act and Food and Drug Regulation (DNHW, 1977), que estabelecem a ausência de Salmonella em $25 \mathrm{~g}$ do produto. 


\section{2 .5 - Fungos e leveduras}

Os resultados da Tabela 2 para esses microrganismos mostram variações de $1,5 \times 10^{2}$ à $6,7 \times 10^{2}$ microrganismos/g para leite em pó integral e contagem nula à $4,2 \times 10^{1}$ microrganismos/ $g$ para leite em pó desnatado, os quais são menores do que os va lores estabelecidos pela CNNPA (1978), que são no mäximo $10^{3}$ organismos/g de produto. A presença desses organismos em leite em pó pode indicar uma possível contaminação durante o acondicio namento do mesmo.

\section{$5.2 .6-$ Psicrotröficos.}

Tanto as amostras ircubadas à $210 \mathrm{C} / 25$ horas como as incubadas à $79 \mathrm{C} / 10$ dias, não apresentaram nenhum desenvolvimento, indicando, portanto, a ausência desses organismos no leite em pó. Isso está de acordo com a maioria dos autores (WITTER, 1961 e THOMAS e DRUCE, 1969), que afirmam que os organismos psicrotróficos não sobrevivem à uma pasteurização adequada, embora mais recentemente (WATROUS et ali $i$, 1971 e PATEL e BLANKENAGEL, 1972), demonstraram que um pequeno nümero de psicrotróficos pode sobreviver à pasteurização. E sabido tambēm que a presença de microrganismos psicrotróficos no leite e seus derivados pode afe tar difetamente as suas qualidades (WEICKBACH e LANGLOIS, 1977). 


\section{$5.2 .7-$ Termófilos}

As contagens para esses organismos oscilaram de $3,2 \mathrm{x}$ $10^{2} \bar{a} 6,1 \times 10^{2}$ microrganismos/g para leite em pö integral e de $5,0 \times 10^{1}$ à $1,1 \times 10^{2}$ microrganismos/g para leite em pó desnatado (Tabela 2). Embora a CNNPA (1978) não estabeleça limites pạ ra a presença desses organismos em leite e derivados, é sabido que tais microrganismos quando presentes em leite em pó, repre sentam um risco para a qualidade dos produtos em que se utilizam leite em pó reconstituído (THOMPSON et alii, 1978). Desta forma, seria interessante que padrões fossem também estabelecidos para microrganismos termófilos, uma vez que, o processamento tér mico que o leite recebe durante a sua desidratação não é suficiente para eliminar todas as bactérias presentes (KEOGH, 1971).

\section{$5.2 .8-$ Enterococos}

As amostras de leite em pó analisadas (Tabela 2), mostram a ausência total desses microrganismos. Apesar de não exis tirem padrões nacionais para a presença de tais microrganismos nesse produto, os dados encontrados estão condizentes com aqueles estabelecidos pela American Public Health Association (1967),

que I imitam a presença de enterococos a não mais que $10^{3}$ organismos/g. Isto porque esses organismos além de causarem alterações no sabor e aroma do leite e derivados (WASHAM et alii, 1977), 
podem se constituir em agentes causais de infecções ao homem (BRYAN, 1973).

\section{$5.2 .9-$ Proteoliticos}

As contagens de proteolíticos (Tabela 2), para todas as amostras analisadas, mostraram variações de $1,6 \times 10^{3}$ à 1,9 $\times 10^{3}$ microrganismos/g para leite em pó integral e de $9,5 \times 10^{2}$ à $1,3 . x 10^{3}$ microrganismos/g para leite em pó desnatado. Apesar da não existência de limitações para a presença desses microrganismos em produtos làteos, é de grande importância que o nümero deles seja reduzido, uma vez que, eles podem causar alterações no sabor e aroma dos diferentes produtos de leite (MICKELSON et alii, 1967 ; CHUNG e CANNON, 1971 e MORENO e KOSIKOWSKI, 1973).

\section{$5.2 .10-\underline{\text { Lipoliticos }}$}

Os números de lipoliticos encontrados nas amostras an a 1 isadas (Tabela 2), são relativamente baixos, variando de $6,0 \mathrm{x}$ $10^{1}$ à $2,3 \times 10^{2}$ microrganismos/g para leite em pó integral e de $5,0 \times 10^{1}$ à $1,6 \times 10^{2}$ microrganismos/g para leite em pó desnatado. Entretanto, a presença desses microrganismos pode signifi car uma alta contaminação da matéria prima (leite), o que consequentemente, poderá trazer problemas para a conservação do leite 
desidratado, pois os tratamentos térmicos a que è submetido durante o processamento, não são suficientes para destruir as 1 ip $\underline{a}$ ses produzidas anteriormente (NASHIF e NELSON, 1953 ; PINHEIRO et alii, 1965 e LAW et alii, 1976).

\section{$5.2 .11-$ Esporulados aeröbicos}

A Tabela 2 mostra as contagens para o grupo de esporulados aeröbicos, que variaram de $5,0 \times 10^{2}$ à $6,3 \times 10^{2}$ microrganismos/g para leite em pó integral e de $5,5 \times 10^{1}$ à $1,7 \times 10^{2} \mathrm{mi}$ crorganismos/g para leite em pó desnatado. Esses resultados são intermediārios àqueles encontrados por GOLDONI et alii (1977), em leite pasteurizado tipo $C$, porém, superiores àqueles verificados por BRUM e MUSSOI (1974), no mesmo tipo de leite. Isto pode indicar que os tratamentos térmicos empregados no processamen to do leite em pó não foram suficientes para a completa destruição desses microrganismos.

$5.3-$ Manteigas

\section{$5.3 .1-$ Contagem total}

As contagens totais obtidas para as amostras analisadas (Tabela 3), variaram de $1,8 \times 10^{6}$ à $2,5 \times 10^{6}$ microrganis - 
mos/g para manteiga sem sal e de $1,1 \times 10^{6}$ à $1,5 \times 10^{6}$ microrganismos/g para manteiga com sal. Os resultados obtidos são inferiores aos nümeros médios encontrados na contagem total de ger mes feita por BRUM (1974), também em amostras de manteigas, que foram de $2,9 \times 10^{6}$ microrganismos/ml de produto. Não existem pạ droẽs nacionais em relação à contagens totais para manteigas,mas números elevados de microrganismos indicam possíveis falhas durante o processamento e acondicionamento do produto e constituem um perigo em potencial para a qualidade do alimento, uma vez que quando altas contagens microbianas são observadas, hä maior probabilidade da presença de organismos patogênicos e/ou deterioradores no produto.

\section{3 .2 - Coliformes}

A Tabela 3 mostra os resultados obtidos para colifor mes totais nas amostras utilizadas neste trabalho, os quais apre sentaram variações de $2,5 \times 10^{4}$ à $2,8 \times 10^{4}$ microrganismos/g para manteiga sem sal e de $1,0 \times 10^{4}$ à $1,8 \times 10^{4}$ microrganismos $/ g$ para manteiga com sal. Nenhuma das amostras de manteiga com sal apresentou contagens tanto para $E$. coli como para coliformes fecais, porém a amostra A de manteiga sem sal apresentou o mesmo nümero para E. coli e coliformes fecais, ou seja, $6,0 \times 10^{2}$ e a amostra $\leq$ também apresentou o mesmo valor para $E$. coli e coli formes fecais, ou seja, $5,0 \times 10^{2}$. Os resultados para colifor- 
mes totais são inferiores aos obtidos por BRUM (1974), que tiveram média de $4,5 \times 10^{4}$ microrganismos $/ \mathrm{m} 1$. Segundo o mesmo autor a presença de microrganismos coliformes em alimentos sempre ind ca falta de higiene durante a obtenção da matēria prima, manipulação ou durante as fases da industrialização. De acordo com a American Association of Medical Milk Comissions (A.A.M.M.C., 1960), a manteiga elaborada com métodos sanitärios adequados não deve conter mais de 10 coliformes/m1. Apesar da não existência de padróes nacionais para esse grupo de organismos, sabe-se que coliformes são indicadores de falhas no processamento e sua presença em nümeros elevados nos derivados do leite é normalmente devido a contaminações após a pasteurização (THOMSON, 1950).

\section{$5.3 .3-$ Staphyzococcus}

Os resultados obtidos para $S$. aureus nas amostras analisadas (Tabela 3), mostraram variações de $8,0 \times 10^{2}$ à $1,8 \times 10^{3}$ microrganismos/g para manteiga sem sal e contagem nula à $3,2 x$ $10^{3}$ microrganismos/g para manteiga com sal. Embora a CNNPA não tenha estabelecido padrões para a presença desse microrganismo nesse produto as contagens encontradas evidenciam a ocorrência de possiveis falhas na pasteurização do creme para elaobração da manteiga, uma vez que Staphylococcus coagulase positivos não sobrevivem à uma pasteurização bem feita (TROLLER, 1976). 


\section{$5.3 .4-$ Salmonelza}

De acordo com os padrões apresentados pela CNNPA (1978), esse organismo não deve aparecer em $25 \mathrm{~g}$ do produto. Entretan to, os resultados da Tabela 3 , mostram que uma das amostras de manteiga sem sal e outra amostra de manteiga com sal, foram pos $\underline{i}$ tivas para Salmonelza, o que as tornam veículos de infecções a 1 imentares.

\section{$5.3 .5-$ Fungos e leveduras.}

As contagens da Tabela 3 para esses microrganismos mos tram oscilações de $9,7 \times 10^{3}$ à $1,4 \times 10^{4}$ microrganismos/g para manteiga sem sal e de $9,8 \times 10^{3}$ à $1,0 \times 10^{4}$ microrganismos/g para manteiga com sal. Esses resultados são inferiores aos núme ros obtidos para esses microrganismos no trabalbo de BRUM (1974), que mostraram variação de $2,0 \times 10^{2}$ à $6,8 \times 10^{5}$ microrganismos / m1. A CNNPA ainda não estabeleceu limites para a presença desses microrganismos em derivados do leite, embora o número deva ser o mais reduzido possível, uma vez que a presença de fungos é aceita como causa de rejeição de um produto alimentício (HOBBS e GILBERT, 1974). Os defeitos normalmente encontrados em mantei gas, devido ao crescimento de fungos, são a discoloração da superfície do produto e produção de sabores desagradáveis em razão de suas caracteristicas oxidativas e lipoliticas. Porém,os fun 
gos causadores desses defeitos, são destruídos pela pasteurização e suas presenças no creme pasteurizado e na manteiga, se de vem à falhas no processamento ou à recontaminação (FOSTER et alii, 1957 ).

\section{3 .6 - Psicrotróficos}

Os valores encontrados para esses microrganismos nesse produto (Tabela 3), também mostram que incubação à $7: C / 10$ dias, e à 21:C/25 horas são equivalentes, como foi demonstrado por OLIVERIA e PARMELEE (1976), uma vez que no presente trabalho, pa् ra as amostras de manteiga sem sal as variações foram de $1,3 \mathrm{x}$ $10^{4}$ à $1,7 \times 10^{4} \mathrm{microrganismos} / \mathrm{g}$ para incubação à $70 \mathrm{c} / 10$ dias e de $1,1 \times 10^{4} \bar{a} 1,5 \times 10^{4}$ microrganismos/g para incubação à $2190 / 25$ horas, enquanto que para as amostras de manteiga com sal as osci 1 ações foram de $7,3 \times 10^{2}$ à $8,1 \times 10^{2} \mathrm{microrganismos} / \mathrm{g}$ para incu bação à $70 \mathrm{c} / 10$ dias e de $6,8 \times 10^{2}$ à $8,1 \times 10^{2} \mathrm{microrganismos} / \mathrm{g}$ para incubçção à 210 C / 25 horas. Valores superiores foram encon trados por BRUM (1974), em amostras de manteiga, com variação de $3,0 \times 10^{3}$ à $1,2 \times 10^{6}$ psicrotróficos/m1, com valor médio de 9,5 x $10^{4}$ psicrotróficos/ml. Não existem limitações para a presença desses organismos em produtos läteos, mas a ocorrência desses mi crorganismos pode ser aliada à falhas no processamento e acondicionamento, jà que esses microrganismos são na sua grande maioria destruídos por pasteurização adequadamente conduzida. Os mi 
crorganismos psicrotróficos são indesejäveis nos derivados do leite por alterarem suas qualidades, principalmente quando estes são mantidos por longos períodos à temperaturas de refrigeração (WEICKBACH e LANGLOIS, 1977).

\section{$5.3 .7-$ Termófilos}

As contagens para esses microrganismos nas amostras a nalisadas (Tabela 3 ), apresentaram variações de $3,1 \times 10^{2}$ à 4,4 $\times 10^{2}$ microrganismos/g para manteiga sem sal e de $1,3 \times 10^{2}$ à $2,0 \times 10^{2}$ microrganismos/g para manteiga com sal. Não foram ain da estabelecidos padrões para esses organismos em leite e deriva dos, mas, sabe-se que muitos organismos termöfilos, produzem esporos que sobrevivem aos tratamentos térmicos empregados na elaboração da manteiga, e, assim, podem permanecer no alimento e de acordo com a temperatura de armazenamento, germinarem e altera rem a qualidade do produto (KEOGH, 1971).

\section{$5.3 .8-$ Enterococos}

A Tabela 3 mostra oscilações de $2,7 \times 10^{2}$ à $5,6 \times 10^{2}$ microrganismos/g para manteiga sem sal e de 7,0 x $10^{1}$ à $1,3 \times 10^{2}$ microrganismos/g para manteiga com sal, nas amostras utilizadas neste trabalho. Padrões nacionais para a presença desses orga- 
nismos em manteiga ainda não foram propostos, mas a American Public Health Association (1967), estabelece que um alimento não deve conter mais do que $10^{3}$ enterococos/g. Pelos resultados obtidos, tanto as amostras de manteiga sem sal como as de manteiga com sal, podem ser enquadradas no padrão acima citado. Esses mi crorganismos quando aparecem em números elevados num alimento,po dem causar alterações nas suas qualidades e serem agentes causais de infecções ao homem (BRYAN, 1973), tornando-se clara a necessidade do estabelecimento de padrões nacionais para a presença des ses microrganismos em alimentos.

\subsection{9 - Proteoliticos}

Variações de $1,1 \times 10^{5}$ à $1,2 \times 10^{5} \mathrm{microrganismos} / \mathrm{g} \mathrm{pa}$ ra manteiga sem sal e de $1,6 \times 10^{4}$ a $2,0 \times 10^{4}$ microrganismos $/ g$ para manteiga com sal, foram encontradas nas amostras analisadas (Tabela 3). Embora não existam limitações para a presença des ses microrganismos em alimentos, é importante que o nümero deles seja o mais reduzido possivel, pois värios trabalhos jä mostra ram que as proteases produzidas por tais organismos alteram as qualidades dos derivados do leite (MICKELSON et a $i$ i, 1967 ; CHUNG e CANNON, 1971 e MORENO e KOSIKOWSKI, 1973). 


\section{$5.3 .10-$ Lipoliticos}

Os números encontrados para esses microrganismos nas amostras utilizadas neste trabalho (Tabela 3), mostram varia ções de $1,1 \times 10^{3}$ à $1,7 \times 10^{3} \mathrm{microrganismos} / \mathrm{g}$ para manteiga sem sal e de $1,0 \times 10^{3}$ à $1,1 \times 10^{3}$ microrganismos/g para manteiga com sal. Organismos lipoliticos podem crescer em cremes e manteigas refrigerados, acarretando o desenvolvimento de sabor e aroma amargos (ANDERSON e HARDENBERGH, 1932). Seria, portanto, interes sante que maiores cuidados fossem tomados durante elaboração, acondicionamento e distribuição desses produtos, para se evitar a presença desses microrganismos e consequente alteração de suas qualidades organoléticas. 


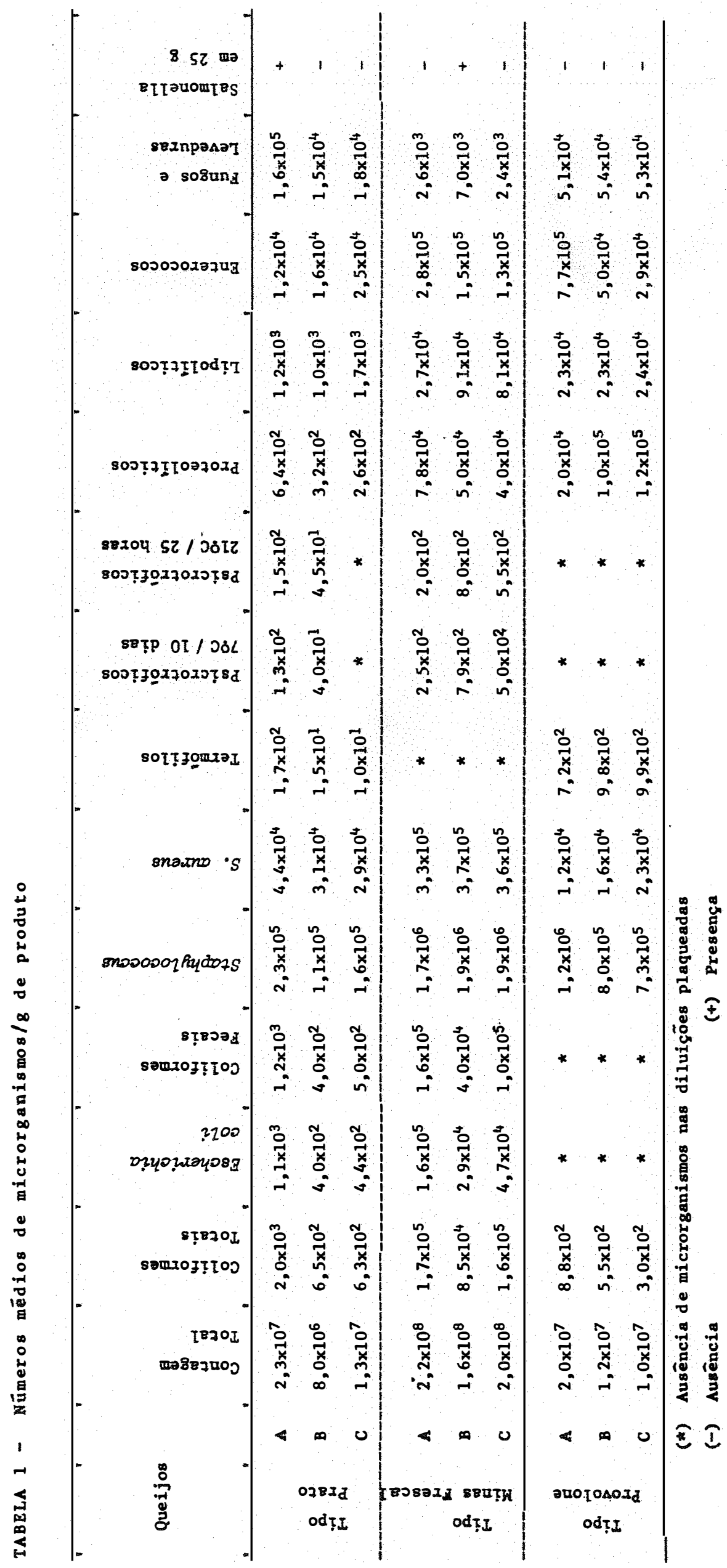




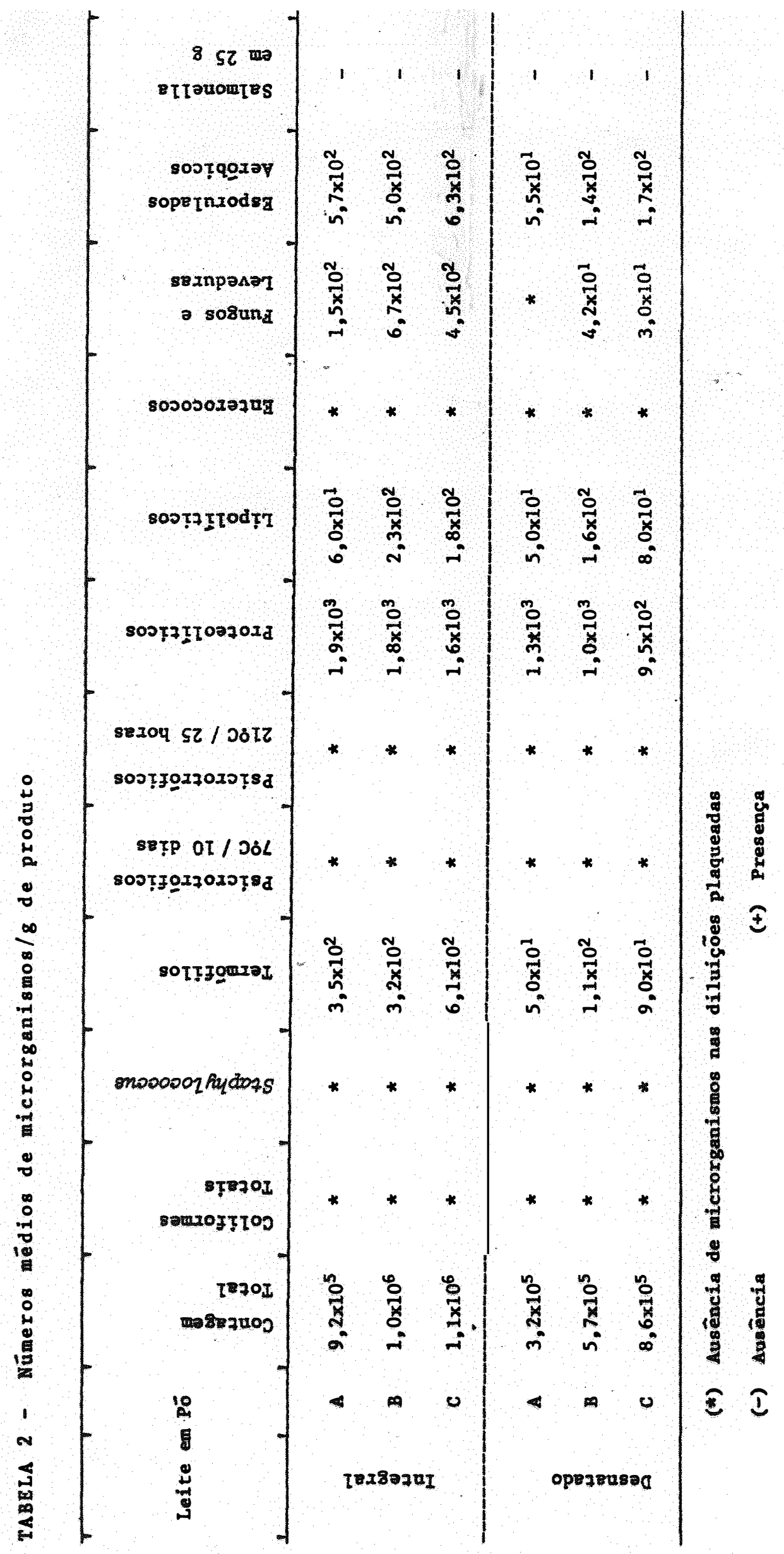




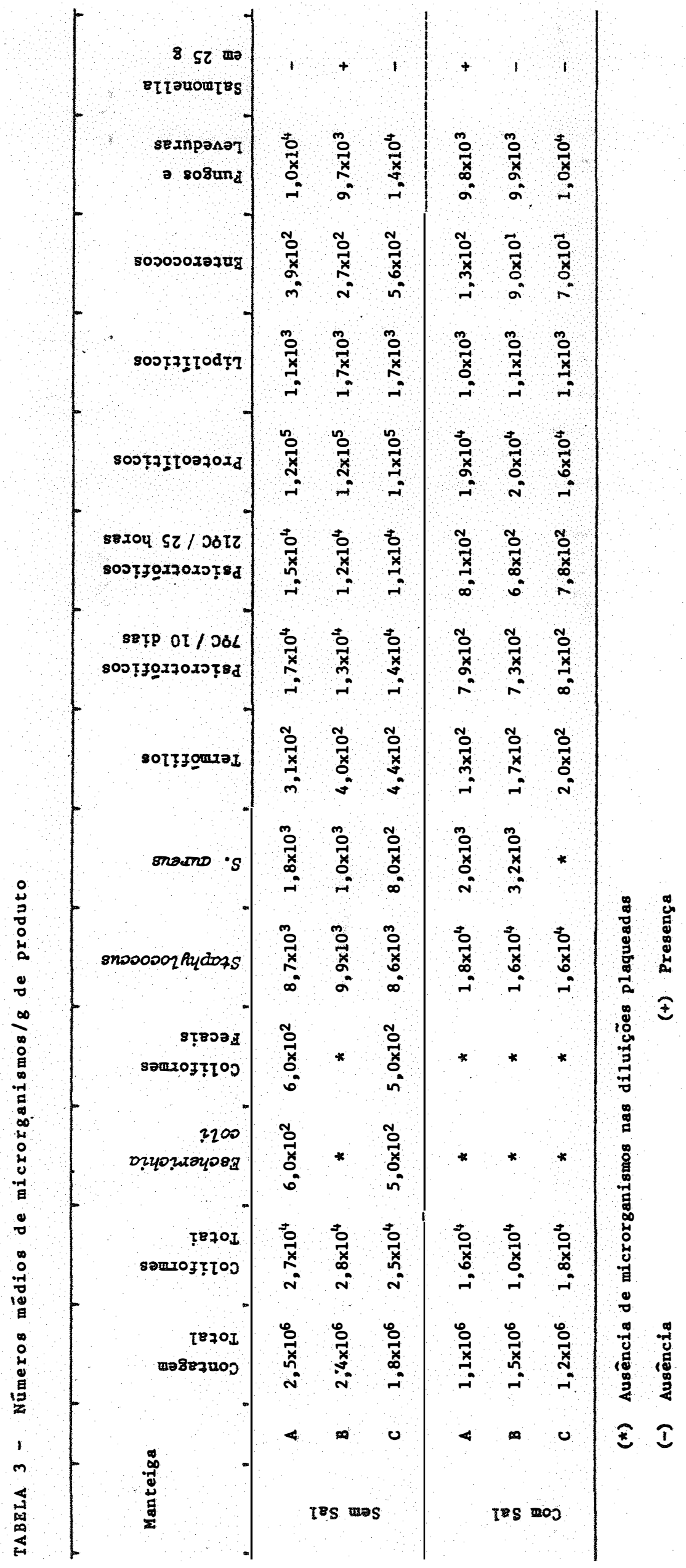


6 - CONCLUSOES

Os resultados do presente trabalho, permitem algumas conclusões gerais, relacionadas com a qualidade de alguns deri vados do leite, em função dos tipos de microrganismos encontra dos:

a - nümero e as espécies de microrganismos encontrados nos derivados do leite, indicam que hà necessidade de maiores cuidados higiênicos no processamento, manuseio, transporte e distribuição desses produtos e também na higieniza ção dos equipamentos que entram em contato direto com tais derivados.

b - A presença de microrganismos patogênicos nas amostras de derivados do leite analisadas, evidencia que melhores con 
troles nas técnicas de processamento devem ser realizados, uma vez que esses microrganismos constituem perigo em potencial, sob o ponto de vista da saūde pūblica.

c - Com exceção do leite em pó, todos os derivados do leite analisados apresentaram contagem de patogênicos (Coliformes, Coliformes Fecais, Enterococos, Staphylococcus e Salmonel 2a) quase sempre superiores aos limites estabelecidos pela Comissão Nacional de Normas e Padrões para Alimentos.

d - As contagens de microrganismos (Psicrotróficos, Proteolíti cos, Lipoliticos, Fungos e Leveduras e Enterococos), principais causadores de alterações de sabor e aroma dos produtos 1äteos, foram de uma maneira geral elevadas, o que concore para o curto período de vida útil e à má qualidade desses produtos.

e - Os resultados encontrados demonstram também que um maior controle por parte dos poderes püblicos deve ser executado para se evitar a distribuição e consumo de tais produtos.

f - Devido a equivalência entre as contagens de psicrotróficos a $79 \mathrm{C} / 10$ dias e a $219 \mathrm{C} / 25$ horas, torna-se evidente que a $\vec{u} 1$ tima condição $\vec{e}$ a mais indicada para a enumeração desses microrganismos em derivados do leite, em razão da maior ra pidez na obtenção dos resultados. 
f - Dadas as altas contagens de microrganismos alteradores das propriedades organolëticas (sabor e aroma) encontradas, po de-se concluir que o estabelecimento de padröes para tais organismos em derivados do leite, se faz necessário, para uma melhor avaliação da qualidade desses produtos. 
This work was undertaken to identify the presence of pathogenics and quality deteriorating microorganisms in some dairy products, such as cheese ("Prato", "Minas Frescal" and "Provolone"), butter (salty and unsalty) and powder milk (whole and skimmilk). Commercial samples were taken and analysed for: Total Count, Coliforms, Fecal Coliforms, StaphyZococcus, Psychrotrophs, Thermophilics, Proteolytics, Lipolytics, Enterococci, SaZmonelZa, and Molds and Yeasts.

The isolation of the microorganisms followed the procedures described by SHARF (1972). The identification was done according to the Standard Methods for the Examination of Dairy Products (A.P.H.A., 1972), Bergey's Manual of Determinative Bac 
teriology (BUCHANAN e GIBBONS, 1975) and Laboratory Exercices for Food Microbiology (BANWART, 1975).

The following ranges of contamination per gram were found for "Prato", "Minas Frescal" and "Provolone" cheeses,res pectivily: Standard Plate Count: $8,0 \times 10^{6}$ to $2,3 \times 10^{7}, 1,6$ $\times 10^{8}$ to $2,2 \times 10^{8}$ and $1,0 \times 10^{7}$ to $2,0 \times 10^{7}$; Coliform P1ate Count: $6,3 \times 10^{2}$ to $2,0 \times 10^{3}, 8,5 \times 10^{4}$ to $1,7 \times 10^{5}$ and 3,0 $\times 10^{2}$ to $8,8 \times 10^{2}$; Escherichia coli Count: $4,0 \times 10^{2}$ to 1,1 $\times 10^{3}, 2,9 \times 10^{4}$ to $1,6 \times 10^{5}$ and none of the "Provolone" chee se samples showed the presence of this microorganism; Fecal Coliform Count: $4,0 \times 10^{2}$ to $1,2 \times 10^{3}, 4,0 \times 10^{4}$ to $1,6 \times 10^{5}$ and none fecal coliform was present in the "Provolone" cheese samples; Staphyzococcus Count: $1,1 \times 10^{5}$ to $2,3 \times 10^{5}, 1,7$ $\times 10^{6}$ to $1,9 \times 10^{6}$ and $7,3 \times 10^{5}$ to $1,2 \times 10^{6} ; S$. aureus Count: $2,9 \times 10^{4}$ to $4,4 \times 10^{4}, 3,3 \times 10^{5}$ to $3,7 \times 10^{5}$ and $1,2 \times 10^{4}$ to $2,3 \times 10^{4}$; Thermophilic Count: $1,0 \times 10^{1}$ to $1,7 \times 10^{2}$, absence in "Minas Frescal" samples analysed and $7,2 \times 10^{2}$ to $9,9 \times 10^{2}$; Psychrotrophs Count (79C/10 days): none to $1,3 \times$ $10^{2}, 2,5 \times 10^{2}$ to $7,9 \times 10^{2}$ and absence in all "Provolone" samples worked; Psychrotrophs Count (219C/25 hours): none to $1,5 \times 10^{2}, 2,0 \times 10^{2}$ to $8,0 \times 10^{2}$ and absence in al1 "Provolone" samples analysed ; Proteolytics Count: $2,6 \times 10^{2}$ to $6,4 \mathrm{x}$ $10^{2}, 4,0 \times 10^{4}$ to $7,8 \times 10^{4}$ and $2,0 \times 10^{4}$ to $1,2 \times 10^{5}$; Lipo1ytics Count: $1,0 \times 10^{3}$ to $1,7 \times 10^{3}, 2,7 \times 10^{4}$ to $9,1 \times 10^{4}$ and $2,3 \times 10^{4}$ to $2,4 \times 10^{4} ;$ Enterococci Count: $1,2 \times 10^{4}$ to 
$2,5 \times 10^{4}, 1,3 \times 10^{5}$ to $2,8 \times 10^{5}$ and $2,9 \times 10^{4}$ to $7,7 \times 10^{5}$; Molds and Yeasts Count: $1,5 \times 10^{4}$ to $1,6 \times 10^{5}, 2,4 \times 10^{3}$ to $7,0 \times 10^{3}$ and $5,1 \times 10^{4}$ to $5,4 \times 10^{4} ;$ Salmonezla: one sam ple of "Prato" cheese and one of "Minas Frescal" cheese were po sitive for this organism and all samples of "Provolone" cheese were negative.

The counts per gram found for salty and unsalty butter samples, were respectivily: Standard Plate Count: $1,1 \times 10^{6}$ to $1,5 \times 10^{6}$ and $1,8 \times 10^{6}$ to $2,5 \times 10^{6}$; Coliform Plate Count: 1,0 $\times 10^{4}$ to $1,8 \times 10^{4}$ and $2,5 \times 10^{4}$ to $2,8 \times 10^{4} ; E$. coli and Fecal Coliforms Counts: no fecal coliform was detected in salty butter samples and none to $6,0 \times 10^{2}$ in unsalty butter samples; Staphyzococcus Count: $1,6 \times 10^{4}$ to $1,8 \times 10^{4}$ and $8,6 \times 10^{3}$ to $9,9 \times 10^{3} ; 5$. aureus Count: none to $3,2 \times 10^{3}$ and $8,0 \times 10^{2}$ to $1,8 \times 10^{3}$; Thermophilic Count: $1,3 \times 10^{2}$ to $2,0 \times 10^{2}$ and $3,1 \times 10^{2}$ to $4,4 \times 10^{2}$; Psychrotrophs Count (70C/10 days): 7,3 $\times 10^{2}$ to $8,1 \times 10^{2}$ and $1,3 \times 10^{4}$ to $1,7 \times 10^{4} ;$ Psychrotrophs Count (21:C / 25 hours): $6,8 \times 10^{2}$ to $8,1 \times 10^{2}$ and $1,1 \times 10^{4}$ to $1,5 \times 10^{4}$; Proteolytics Count: $1,6 \times 10^{4}$ to $2,0 \times 10^{4}$ and $\quad 1,1 \times 10^{5}$ to $1,2 \times 10^{5}$; Lipolytics Count: $1,0 \times 10^{3}$ to $1,1 \times 10^{3}$ and $1,1 \times 10^{3}$ to $1,7 \times 10^{3}$; Enterococci Count: $7,0 \times$ $10^{1}$ to $1,3 \times 10^{2}$ and $2,7 \times 10^{2}$ to $5,6 \times 10^{2} ;$ Molds and Yeasts Count: $9,8 \times 10^{3}$ to $1,0 \times 10^{4}$ and $9,7 \times 10^{3}$ to $1,4 \times 10^{4}$; Salmonelza: was detected in one of both salty and unsalty butter. 
For whole powder milk and dehidrated skimmilk the coun tings were respectivily:... Standard Plate Count: $9,2 \times 10^{5}$ to $1,1 \times 10^{6}$ and $3,2 \times 10^{5}$ to $8,6 \times 10^{5} ;$ No coliforms neither Staphylococcus were detected in both whole powder and dehidrated skimmilk; Thermophilic Count: $3,2 \times 10^{2}$ to $6,1 \times 10^{2}$ and $5,0 \times 10^{1}$ to $1,1 \times 10^{2} ;$ Psychrotrophs (79C/10 days and $219 \mathrm{C} /$ 25 hours) and Enterococci Counts: not found in all samples an a lysed; Proteolytics Count: $1,6 \times 10^{3}$ to $1,9 \times 10^{3}$ and $9,5 \times$ $10^{2}$ to $1,3 \times 10^{3}$; Lipolytics Count: $6,0 \times 10^{1}$ to $2,3 \times 10^{2}$ and $5,0 \times 10^{1}$ to $1,6 \times 10^{2}:$ Molds and Yeasts Count: $1,5 \times 10^{2}$ to $6,7 \times 10^{2}$ and none to $4,2 \times 10^{1}$; Aexobic spore forming Count: $5,0 \times 10^{2}$ to $6,3 \times 10^{2}$ and $5,5 \times 10^{1}$ to $1,7 \times 10^{2} ;$ SaI monella: all samples were negative for this organism.

The fairly high Total Counts, Coliforms, Fecal Coli forms, Staphylococcus, $S$, aureus, Enterococci, Proteolytics, Li polytics, Psychrotrophs, in most samples of dairy products analysed in this work and the presence of Salmonella in some of them, reaveled that they should all be rejected for people consuming, once, most pathogenic microorganism countings are above thouse standards stablished by the Comissão Nacional de Normas e Padróes para Alimentos.

on the other hand, these high microbial levels could be an indication of the poor hygienic conditions in the dairy plants and handling of these products at the retail level. 
ADAMS, D. M. et $a$ Li $i, 1975$. Heat resistant proteases produced in milk by psychrotrophic bacteria of dairy origin. J. Dairy Sci. 58: 828-834.

AMERICAN ASSOCIATION OF MEDICAL MILK COMISSIONS, 1960. Normas para el examen de los productos lacteos. Organización Panamericana de la Salud, $11^{\mathrm{a}}$ ed., Washington, E.E.U.U., p. 156 .

AMERICAN DRY MILK INSTITUTE, 1973. Standards for grades of dry milks, including methods of analysis. Bulletin 916. Am. Dry Milk Inst. Inc., Chicago, IL.

AMERICAN PUBLIC HEALTH ASSOCIATION, Inc., 1960. Standard Methods for the examination of dairy products. $11^{\text {th }}$ ed. New York, N. Y. 
AMERICAN PUBLIC HEALTH ASSOCIATION, 1967. Standard methods for the examination of dairy products. $12^{\text {th }}$ ed. New York, N. $Y$.

AMERICAN PUBLIC HEALTH ASSOCIATION, 1972. Standard methods for the examination of dairy products. 13. ed. American Public Health Association, Inc., Washington, D.C., 345 p.

ANDERSON, J. A. e J. C. HARDENBERGH, 1932. Deterioration of cream by a lipolytic bacterium. J. Bacteriol. 23: 59 .

ANDREY, J. Jr. e W. C. FRAZIER, 1959. Psychrophiles in milk held two days in farm bulk cooling tanks. J. Dairy Sci. 42: $1781-1784$.

ANDREWS, R. H. e O. W. KAUFFMAN, 1953. The destruction of psychrophilic bacteria in milk by HTST pasteurization based on thermal death times studies. J. Dairy Sci. 36: 570-571.

ASHTON, T. R., 1950. Some bacteriological aspects of the deterioration of pasteurized milk. J. Dairy Res. 17: 261-287.

ASSOCIATION OF OFFICIAL ANALYTICAL CHEMISTS, 1970. Methods of analysis. J. Assoc. Off. Anal. Chem. 53: 845-852.

BABEL, F. J., 1953. Activity of bacteria and enzymes in raw milk held at 4,4:C. J. Dairy Sci. 36: 562 .

BANWART, G. J., 1975. Laboratory exercices for food microbiolo. gy. The Ohio State University, Columbus, Ohio, $176 \mathrm{p}$.

BRYAN, F. L., 1973. Diseases transmitted by foods. (A Classification and Summary). U. S. Depart. of Health, Education, and Welfare, Public Health Service, $63 \mathrm{p}$. 
BUCHANAN, R. E. e N. E. GIBBONS, 1975. Bergey's Manual of Determinative Bacteriology. $8^{\text {th }}$ ed. Baltimore, Williams and Wilkins, p. 292-295, 298-317, 484-485 and 504-505.

BERGDOLL, M. S., 1969. Bacterial toxins in food. Fd. Technol. Champaign, 23: 530-533.

BERGDOLL, M. S., 1970. Enterotoxins. In: T. C. Montie, S. Ka dis, and S. J.Aj1. (ed.), Microbial Toxins. Vol. 3. Academic Press. New York and London.

BLADSAVLE, C. H. et alii, 1972. Isolation and identification of psychrophilic species of Clostridium from milk. Appl. Microbiol. 24: 699-702.

BRINDLEY, M., 1954. The surface microflora of stilton cheese normal and slip-coat. J. Dairy. Res. 21: 83-100.

BRUM, M. A., 1974. Pesquisa dos agentes microbiológicos que mais frequentemente determinam alteraçós na manteiga durante a conservação. Revista do Instituto de Laticinios Cândido Tostes, 29 (172): 11-20.

BRUM, M.A. e MUSSOI, E., 1974. Aspéctos microbiológicos do leite pasteurizado consumido em Santa Maria, RS. II. Termodüricos, esporulados e germes termöfilos. Revista do Centro de Ciências Rurais, 44: 383-388.

CHUNG, B. H. e R. Y. CANNON, 1971. Psychrotrophic spore-forming bacteria in raw milk supplies. J. Dairy Sci. 54: 448 . 
COLLINS-THOMPSON, D. L, et alii, 1977. Microbiological standards for cheese: survey and viewpoint of the Canadian Health Protection Branch. J. Food Protect. 40: 411-414.

COMISSÃO NACIONAL DE NORMAS E PADRÕES PARA ALIMENTOS, 1978 . Resolução aprovada pela CNNPA. Resolução no 13/78. Diārio oficial da União, 25 de julho. p. 11.616-11.617.

COUSINS, C. M. et alii, 1977. The bacteriological quality of milk for cheddar cheese making. Dairy. Ind. Int. 42: 1217 .

CROSSLEY, E. L. e W. A. JOHNSON, 1942. Bacteriological aspects of the manufacture of spray-dried milk and whey powders, in cluding some observations concerning moisture content and solubility. J. Dairy Res. 13: 5 .

DAVIS, P. A., 1951. The effect of cold on microorganisms in re lation to dairying. Proc. Soc. App1. Bacterio1. 14: 216 .

DELAY, P. D., 1947. The significance of the coliform test in pasteurized milk. J. Milk, Food Technol. 10: 297-299.

DNHW, 1977. Food and Drugs Act and Food and Drug Regulations with Amendments to August 25, 1976. Dept. of National Health and Welfare, Minister of Supply and Services Canada, Ottawa.

DIFCO LABORATORIES, INC., 1957. Difco Manual of dehydrated cul ture media and reagents. $9 \mathrm{th}^{\mathrm{E}}$ ed. Difro Laboratories, Inc. Detroit, Mich. p. 151 .

DONNELLY, C. B. et alii, 1968. Production of enterotoxin A in milk. Appl. Microbiol. 16: 917-924. 
EDDY, B. P., 1960. The use of the term psychrotrophic.

$\underline{\mathrm{J}}$ Appl. Bacteriol. 23: 189-190.

EDWARDS, P. R. e M. M. GALTON, 1967. Samonellosis. Adv. Vet. Sci. 11: $1-63$.

ELLIKER, P. R. et alii, 1964. Psychrophilic bacteria and Keeping quality of pasteurized dairy products. J. Milk Food, Technol. 27: 69-75.

ERNSTROM, C. A., 1954. An early gas defect in pasteurized milk cheddar cheese. Milk Prod. J. 45: 21-42.

FAGERBERG, D. J. e J. S. AVENS, 1976. Enrichment and plating methodology for Salmonella detection in food. A Review. J. Milk Food Technol. 39: 628-646.

FANTASIA, L. D. et alii, 1975. Detection and growth of enteropathogenic Escherichia coli in soft ripened cheese. App1. Microbiol. 29: 179-185.

FOOD AND DRUG ADMINISTRATION, 1972. Bacteriological analyti cal manual. $3^{\text {rd }}$ ed. U. S. Dept. of Health, Education and Welfare, Washington, D. C.

FORD, H. F. e F. J. BABEL, 1969。 Milk quality problems asso ciated with present day marketing. J. Milk Food Technol. 22: $141-144$.

FOSTER, E. M. et alii, 1957. Dairy Microbiology. p. 38-43 e $136-141$. 
FOX, C. W. et alii, 1976. Incidence and identification of phos pholipase C - producing bacteria in fresh and spoiled homo genized milk. J. Dairy Sci. 59: 1.857-1.864.

FRANK, J.P. e E.H. MARTH, 1978. Survey of soft and semisoft cheese for presence of fecal coliforms and serotypes of enteropathogenic Escherichia coli. J. Food. Protect. 41: $198-200$.

FRANK, J.F. et alii, 1977. Survival of enteropathogenic and nonpathogenic Escherichia coli during the manufacture of camembert cheese. J. Food Protect. 40: 835-84?.

FRANK, J.F. et alii, 1978. Behavior of enteropathogenic Es cherichia coli during the manufacture and ripening of brick cheese. J. Food Protect. 41: 111-115.

FRANKLIN, J. G. e M. E. SHARPE, 1963. The incidence of bacteria in cheese milk and cheddar cheese and their association with flavour. J. Dairy Res. 30: 87-99.

FRYER, T. F . E M. E. SHARPE, 1965. A termoduric strain of Streptomyces albus isolated from cheddar cheese. J. Dairy Res. 32: 27-34.

GALTON, M. M. et alii, 1968. Salmonellae in foods and feeds. Review of isolation methods and recommended procedures. U.S. Dept. of Health, Education, and Welfare/Public Health Service. Communicable Disease Center, At lanta, Georgia.

GIBSON, T. e ABD-EL-MALLECK, Y。, 1957. The development of bac terial populations in milk. Canadian J. Microbiol. 3 : 203-213. 
GOEPFERT, J. M. et alii, 1968. Behavior of Salmonella typhimurium during manufacture and curing of cheddar cheese. App1. Microbio1. 16: 862-866.

GOLDONI et alii, 1977. Congresso Nacional de Laticínios, 40, Juiz de Fora. Anais. Juiz de Fora, EPAMIG, Inst. Latic. Candido Tostes, p. 144-149.

GROSSKOPF, J. C. e W. J. HARPER, 1969. Role of psychrophilic sporeformers in long-1ifemilk. J. Dairy Sci. 52: 897 .

HAMMER, B. W. e M. A. COLLINS, 1934. The numbers of 1ipolytic bacteria in various dairy products, as determined with ni1e-blue sulfate. Res. Bull. Ia. Agric. Exp. Sta.no 169.

HARGROVE, R. E. et alii, 1971. A seletive medium and presumptive procedure for detection of Salmonella in dairy products. J. Milk Food Techno1. 34: 6-12.

HARLAND, H. A. et alii, 1952. The effect of the various steps in the manufacture on the extent of serum protein denatura tion in nonfact dry milk solids. J. Dairy Sci. 35: 363 .

HEINEMANN, B., 1957. Growth and thermal destruction of Micro coccus pyogenes var. aureus in heated and raw milk. J. Dairy. Sci. 40: $1.585-1.589$.

HENDRICKS, S. L. et alii, 1959. Staphylococcal food intoxication due to cheddar cheese. J. Milk and Food Technol. 22: $313-317$.

HOBBS, B. C. e J. GILBERT, 1974. Microbiological counts in re lation to food poisoning. Proc. IV Int. Congress Food Sci. and Technol. III: 159-169. 
HOUSE COMMITTEE ON INTERSTATE AND FOREIGN COMMERCE AND THE SENATE COMMITTEE ON LABOR AND PUBLIC WELFARE, 1973. Compila tion of selected public health laws (Join Committee print, $93^{\text {rd }}$ Congress, $1^{\text {st }}$ session). Vol. 2 , Federal Food, Drug and Cosmetics Act. U.S. Government Printing Office, Washington.

JAWETZ, E. et alii, 1970. Microbiologia Médica. 2 a ed. Rio de Janeiro, Edit. Guanabara, p. 175-177.

JENSEN, J.P. et alii, 1975. Role of enterococci in cheddar cheese: Growth of enterococci during manufacturing and cu ring. J. Milk Food Technol. 36: 613-618.

JONES, F. T. e B. E. LANGLOIS, 1977. Microflora of retail fluid milk products. J. Food Protect. 40: 693-697.

JONES, G. A. et alii, 1967. Coliform bacteria in Canadian pasteurized dairy products. Can. J. Public Health 58: 257264 .

JUFFS, H。S. e F. J. BABEL, 1975. Inhibition of psychrotrophic bacteria by lactic cultures in milk stored at low temperatu re. J. Dairy Sci. 58: 1.612-1.619.

KEOGH, B. P., 1971. Reviews of the progress of dairy science. J. Dairy Res. 38: 91-111.

KILBOURNE, 1920. Ninth Ann. Rept., Interntl. Assoc. Dairy and Milk Insp. 111 (Cited in Tanner, F. W., 1944). "The Microbiology of Food". Champaign, Illinois, Garrard Press, $321 \mathrm{p}$. 
KIURU, Von R. et alii, 1971. Die proteolytische aktivitat der psychrotrophen mikroorganismen in der holbehaltermilch. Milchwissenschaft. $26: 138$.

KOSIKOWSKI, F., 1970. Cheese and fermented milk foods. Mi chigan, Edwards Brothers, p. 356 .

LAW, B. A. et alii, 1976. The effect of lipolytic gram-negati ve psychrotrophs in stored milk on the development of rancidity in cheddar cheese. J. Dairy. Res. 43: 459-468.

LUCK, H., 1972. Bacteriological quality tests for bulk-cooled milk. A review. Dairy Sci. Abst. 34: 101-122.

MARKUS, 2. e G. J. SILVERMAN, 1968. Enterotoxin B production by nongrowing cells of Staphylococcus aureus. J. Bacteriol. $96: 1.446-1.447$.

MARIER, R. et alii, 1973. An outbreak of enteropathogenic Escherichia coli foodborne disease traced to imported French cheese. Lancet 2: $1.376-1.378$.

MARTH, E. H. eW. C. FRAZIER, 1957. Bacteriology of milk held at farm bulk cooling tank temperatures. III. Psychrophiles found and their growth. J. Milk Food Technol. 20: 93-99.

MAYERHOFER, H. J. et alii, 1973. Characterization of a heatstable protease of Pseudomonas fluorescens P 26 . App1. Microbiol. 25: 44-48.

MEHLMAN, I. J. et ali $i$, 1974. Problems in the recovery and identification of enteropathogenic Escherichia coli from food. J. Milk Food Technol. 37: 350-356. 
MEHLMAN, I. J. et alii, 1976. Pathogenicity of Escherichia coli recovered from food. J. Ass. Off. Anal. Chem. 59: 67-80.

MICKELSON, R. et alii, 1967. Some chemical and flavour characteristics of a milk proteolysate of Pseudomonas fluores cens. J. Dairy Sci. 50: 172-176.

MINOR, T. E. E E. H. MARTH, 1972. S. aureus and Staphylococ .. cal food intoxications. A Review. The Staphylococci: cha racteristics, isolation and behavior in artificial media. J. Milk Food Technol. 34: 557 .

MORENO, V. e F. V. KOSIKOWSKI, 1973. Peptides, amino-acids and amines liberated from $\beta$-casein by micrococcal cell-free pre parations. J. Dairy Sci. 56: 39 .

MORSE, P. M. et alii, 1968. Investigation of factors contriburing to the bacterial count of bulk tank milk. III. Increase in count, from cow to bulk tank and effects of refri gerated storage and preliminary incubation. J. Dairy. Sci. 51: $1.192-1.206$.

MORSE, S. A. et alii, 1969. Regulation of Staphylococcal enterotoxin B. J. Bacteriol. 98: 4-9.

MOUREY, A. e G. KILBERTUS, 1976. Simple media containing tribu tirin for demonstrating lipolytic bacteria in food and soils. J. Appl. Bacteriol. 40: 47-51.

MUSSOI, E., 1974. Aspectos microbiológicos da flora contaminan te de queijos tipo Prato e Lanche. Boletim do Leite, 552: 21-24. 
NAGUIB, K. H. et alii, 1972. Spray dried milk of the sakha plant. II. Identification of predominating microorga nisms. J. Milk Food Technol. 35: 45 .

NASHIF, S。A. e F. E. NELSON, 1953. The lipase of Pseudomonas fragi. I. Characterization of the enzyme. J. Dairy. Sci. $36: 459-470$.

NATIONAL ACADEMY OF SCIENCES. 1971. Reference methods for the microbiological examination of foods. Foor Protection Com mittee, Food and Nutrition Board, Division of Biology and Agriculture, National Research Counci..

NATIONAL CENTER FOR DISEASE CONTROL. 1970. Staphylococcal food poisoning traced to butter - Alabama. Morbidity Mortality 19: 271 .

OLIVERIA, J . S. e C. E. PARMELEE, 1976. Rapid enumeration of psychrotrophic bacteria in raw and pasteurized milk. J. Milk Food Technol. 39: 269-272.

OVERCAST, W. W. e K. ATMARAM, 1974. The role of BacizZus cereus in sweet curding of fluid milk. J. Milk Food Technol. 37 : $233-236$.

OVERCAST, W. W. e J. D. SKEAN, 1959. Growth of certain lipoly tic microorganisms at $4 \circ \mathrm{C}$ and their influence on free fat acidity and flavour of pasteurized milk. J. Dairy Sci. 42: $1.479-1.485$.

PATEL, G. B. e G. BLANKENAGEL, 1972. Bacterial count of raw milk, and flavour of the milk after pasteurization and storage. J. Milk Food Technol。 35: 203. 
PEDERSON, C. S. e M. W. YALE, 1934. Effect of temperature of incubation upon agar plate count of milk. Am. J。 Public Hea1th $27: 477-484$.

PINHEIRO, A. J. et alii, 1965. Heat stability of lipases of selected psychrophilic bacteria in milk and purdue swisstype cheese. J. Dairy Sci. 48: 983-984.

POZNAFSKY, S. et alii, 1965. La protéolyse de la caséine par les enzymes intracellulaires de certaines bactéries. Le Lait 45: $\quad 3-26$.

PURSCHEL, M. e C. POLLACK, 1972. Proteolytischer Abbau der Micheiweiss - Stoffe durch Bakterien. 2. Mitt. Die Wircung von psychrophilen and milch - saurebildenden bakte rien auf die Eiweisstoffe in der Milch. Die Nahrung. 16: 451 .

RAYMAN, M. K. et ali $i$, 1975. Reassessment of the coagulase and thermostable nuclease tests as a mean of identifying $S$. aureus. App1. Microbio1. 29: 451-454.

$\mathrm{READ}, \mathrm{R}$. B. et alii, 1963. Assay of Staphylococcal enterotoxin in milk by immunodifusion. J. Dairy Sci.46: 598-599.

REITER, B., 1964. Factors affecting the multiplication and sur. vival of coagulase positive staphylococci in cheddar cheese. J. Dairy Res. 31: 261-272。

ROGERS, 1915. Cream and Milk Plant Mthly 4 : 15 (Cited in Tan ner, F. W., 1944. "The Microbiology of Food". Champaign, Illinois, Garrard Press, 321 p. 
ROGICI, F. A. e L. H. BURGWALD, 1952. Some factors which contribute to the psychrophilic count in raw milk. J. Milk Food Technol. 15: 181-195.

RYDER, R. . et alii, 1976. Infantile diarrhea produced by heat-stable enterotoxigenic Escherichia coli. New Eng. J. Med. 295: 849-853.

SACK, R. B., 1975. Human diarrheal disease caused by enteroto xigenic Escherichia coli. Ann. Rev. Microbio1. 28: 333353 .

SAMUELSSON, E. G. e S. HOLM, 1966. Technological principles for ultrahigh heat treatment of milk. XVII Int. Dairy Congr. Munchen, B. 1. 57.

SCOTT, W. J., 1953. Water relations of $S$, aureus at $309 \mathrm{C}$. Aust. J. Biol. Sci. 6 : 549-563.

SHAHANI, K。 M., 1974. Lipases and esterases. Page 181 in Enzymes in Food Processing. G. Reed, ed. Academic Press, New York.

SHARF, J. M., 1972. Métodos recomendados para o exame micro biológico de alimentos. Tradução de M. Falcone, são Pau10, Poligono, p. 187-212.

SHARPE, M. E. et alii, 1962. Staphylococci and micrococci associated with dairying. J. App1. Bacterio1. 25: 403-415.

SPERBER, W. H. e S. R. TATINI, 1975. Interpretation of the tu be coagulase test for identification of $S$. aureus. Appl. Microbio1. 29: 502-505. 
STANIER, R. Y. et alii, 1969. Mundo dos Micröbios. Ed. Edgard Blucher Ltda, SP. - Brasil, p. 334-354.

TAKAHASHI, I. e C. K. JOHNS, 1959. StaphyZococcus aureus in cheddar cheese. J. Dairy Sci. 42: 1.032-1.037.

THOMAS, S. B., 1958. Microrganisms in milk and dairy products. Part II. Dairy Sci. Abstrs. 20: 447.

THOMAS, S. B. e R. G. DRUCE, 1969. Psychrotrophic bacteria in refrigerated pasteurized milk. A Review. Dairy Ind. 34 : 351 .

THOMAS, S. B. e C. V. SEKHAR, 1946. Phychrophilic bacteria in raw and commercially pasteurized milk. Proc. Soc. Appl. Bacteriol. 1: 47 .

THOMAS, S. B. et alii, 1966. The significance of psychrotrophic bacteria in raw milk. Dairy. Ind. 31: 27-32.

THOMSON, G. I., 1950. Coliform bacteria in New Zealand butter. J. Dairy Res. 17: $72-78$.

THOMPSON, S. S. et alii, 1978. Survival of selected organisms during spray drying of skim milk and storage of nonfat dry milk. J. Food Protect. 41: 16-19.

TINUOYE, 0. L. e L. G. HARMON, 1975. Growth of thermoduric psychrotrophic bacteria in refrigerated milk. Am. Dairy Rev. 37: 26-30. 
TROLLER, J.A., 1976. Staphylococcal growth and enterotoxin production factors for control. J. Milk Food Technol. 39: 499-503.

VAN der ZANT, W. C. e F. E. NELSON, 1953. Characteristics of an endocellular proteolytic enzume system of streptococcus Zactis. J. Dairy Sci. 36: 1.212-1.222.

WASHAM \& C. J. et alii, 1977. Heat-resistant psychrotrophic bac teria isolated from pasteurized milk. J. Food Protect. 40: $101-108$.

WATROUS, G. H. et alii, 1971. A survey of the actual and poten tial bacterial keeping quality of pasteurized milk from 50 Pennsylvania dairy plants. J. Milk Food Technol. 34: 145 .

WEICKBACH, L. S. e B. E. LANGLOIS, 1977. Effect of heat treatments on survival and growth of a psychrotroph and on nitro gen fractions in milk. J. Food Protect. 40: 857-862.

WITTER, L. D., 1961. Psychrophilic bacteria. A Review. J. Dairy Sci. 44: 983-1.015.

YALE, M. W., 1943. Significance of the coliform group of bacteria in American cheddar cheese. J. Dairy Sci. 26: 766. (Atstr.).

YANAGIYA, T. et alii, 1973. Changes of milk protein by psy chrotrophic organisms. I. Agr..Chem. Soc. Jap. 47: 259. 